\title{
EL CONCEPTO DE FALSEDAD EN EL FALSO TESTIMONIO UNA INTRODUCCIÓN A LA DOGMÁTICA GENERAL DE LOS DELITOS DE FALSEDAD*
}

\author{
THE CONCEPT OF FALSEHOOD AN INTRODUCTION TO THE \\ GENERAL STUDY OF FALSEHOOD AND FORGERY IN CRIMINAL LAW
}

\author{
JAVIER WILENMANN VON BERNATH ${ }^{* *}$
}

\begin{abstract}
RESUMEN: El presente artículo da cuenta de la posición sistemática de los delitos de falsedad en el derecho penal, así como de la forma en que la dogmática de la Parte Especial puede hacerse cargo de ellos. Para ello, identifica una estructura relacional compartida de estos, la cual se ve ilustrada a partir de su tratamiento dogmático en la determinación del sentido de la expresión "falso" en el falso testimonio.
\end{abstract}

Palabras clave: Derecho penal, falsedad, falso testimonio, teorías de la verdad.

ABSTRACT: The present paper analyses the systematic position and the structure of forgery and other falsehood crimes in criminal law. It describes the relational structure, which all falsehood crimes share. This structure is exemplified by means of a juridical analysis of the term "false" in false testimony (perjury).

Key words: Criminal law, falsehood, perjury, theories of truth.

\section{INTRODUCCIÓN}

El castigo por la producción de falsedad es un rasgo extendido de los sistemas penales modernos desde las codificaciones tempranas ${ }^{1}$. Si bien, en la recepción del delito genéri-

\footnotetext{
* Algunas de las referencias bibliográficas relevantes del artículo me fueron facilitadas por Juan Pablo Mañalich a propósito de un curso sobre delitos de falsedad del que derivó la idea de escribir una serie de artículos. Estoy, por ello, en particular deuda con él al respecto. Agradezco asimismo comentarios y correcciones efectuadas a un borrador de este artículo por el mismo Juan Pablo Mañalich y por Miguel Schürmann. Todos los errores son obviamente de mi responsabilidad.

** Abogado, Licenciado en Ciencias Jurídicas y Sociales, Universidad de Chile (2009), Profesor de Facultad de Derecho, Universidad Adolfo Ibáñez. LLM Universität Regensburg (2012) y candidato a doctor por la Albert Ludwigs Universität Freiburg. Becario DAAD. Correo electrónico: jwilenmann@yahoo.com.

1 Esto es evidente, por ejemplo, en el caso del más antiguo de los delitos de falsedad: el falso testimonio (así también BINDing (1997) pp. 110-112). La punibilidad del falso testimonio puede rastrearse fácilmente incluso hasta el antiguo derecho hebreo, bajo el cual la pena aplicable al falso testimonio debía ser equivalente a la sanción que el falso testigo pretendía fuera aplicada a la víctima: el tratamiento del falso testimonio reflejaba intuiciones básicas sobre justicia retributiva. Esta regla de determinación de la pena también fue recogida durante la codificación temprana. Así lo hacía, por ejemplo, el artículo 361 del Código Penal francés de 1810. Una regla de esta clase puede reconocerse, con modificaciones, en varias codificaciones que siguieron a la codificación francesa. Así, por ejemplo, bajo el artículo 192 del Código Penal para el Reino de Baviera de 1861, o bajo los artículos 215 y 216 del Código Penal belga de 1867. Los artículos 206 y siguientes del Código Penal chileno contenían una regla similar hasta reformas recientes. Sobre la historia del castigo de la falsedad, véase en detalle Merkel (1867) pp. 13 ss. y Berner (1986) pp. 594 ss. En la literatura contemporánea JaKOBS (2000)
} 
co del falsum y de otros delitos derivados de la Lex Cornelia y desarrollados por el derecho común, el objeto de protección ha tendido a variar entre concepciones religiosas-moralizantes $^{2}$, protección de bienes supraindividuales ${ }^{3}$ y protección de intereses individuales ${ }^{4}$, el desarrollo de contextos de acción dependientes de información recibida, como son ante todo la burocracia estatal, la administración de justicia ligada a la comprensión del derecho moderno y la economía capitalista, ha creado una dependencia social de la protección penal frente a la falsedad. Esa dependencia se ve alimentada por la paulatina desaparición de equivalentes funcionales históricos. Así, mientras la imputación a competencia supranatural del castigo del quebrantamiento del juramento ${ }^{5}$ o la tortura como modo de funcionamiento de la administración de justicia ${ }^{6}$ entregaban formas de incentivo a la no producción de falsedad, la sociedad moderna requiere a la vez en mayor medida y con menores formas de control de ausencia de falsedad comunicacional en ciertos contextos de interacción.

A diferencia de otros delitos de larga tradición en el sistema penal y que tampoco se reconducen a las categorías tradicionales de delitos contra intereses individuales, como la prevaricación judicial, varias formas de delitos de falsedad son además recurrentemente imputados. Esta importancia práctica tiende a acrecentarse en el derecho penal chileno, en el que la ausencia de ciertas categorías de delitos contra el patrimonio -ante todo el delito de administración desleal de patrimonio ajeno- produce que, en los conflictos patrimoniales que pretenden ser penalizados por el Estado o por la supuesta víctima, los tipos cuya imputación puede parecer plausible se reduzcan en lo esencial a la estafa, la apropiación indebida y algunos delitos de falsedad. Esto es: pese a su configuración actual

pp. 1-4; Maurach/Schroeder/Maiwald (2005) $\$ 64$ Nm. 1 ss. y $\$ 75$ Nm. 5-6; Müller (2000) pp. 8 ss.; Müller (2012) Vor $\$ \$ 153$ ff. Nm. 3-6; Cramer/Heine (2010) Vorbem. $\$ 267$ ff. Nm. 1-3. En español véase la detallada publicación reciente de Rojas (2012) pp. 547 ss.

2 Este es, en particular, el caso del falso testimonio y de la teoría de la protección del juramento en relación con el perjurio. Al respecto, véase solo Müller (2000) pp. 28-29; y Müller (2012) Vor \$\$ 153 ff. Nm. 3.

3 Sobre la concepción de la fe pública en el siglo XIX, véase solo JaKobs (2000) pp. 5 ss.; Puppe (2013) Nm. 3; MÜller (2000) pp. 31-38; y RoJas (2012) pp. 573 ss.

4 Sobre la deconstrucción del falsum como forma de engaño en la dogmática moderna relacionada con la protección del patrimonio y su diferenciación progresiva, véase JAKOBS (2000) pp. 2-4; MAURACH/SCHROEDER/ Maiwald (2005) \$ 64 Nm. 5; Müller (2000) pp. 30-31; Müller (2012) Vor \$\$ 153 ff. Nm. 4-6 y KINDHÄUSER $(2012) \$ 55 \mathrm{Nm}$. 6. La diferencia que tiende a ser marcada hoy entre protección de la fe pública y protección privada del patrimonio fue, por cierto, desarrollada y por ello conocida por la dogmática del siglo XIX, pero no era marcada con tanto énfasis en esta como tiende a serlo hoy (protección del patrimonio a través de prohibición de mentira vs. protección de la verdad -contenido auténtico- así por ejemplo MaURACH/ Schroeder/Maiwald (2005) $\$ 64 \mathrm{Nm}$. 5). Incluso un defensor de la diferencia de los delitos de falsedad y de los delitos de enriquecimiento patrimonial mediante engaño (delitos derivados del estelionato) como MerKeL (1867) pp. 15 ss., podía reconstruir a la fe pública como el conjunto de signos que implican manifestación falsa de posición de acreedor del autor o de un tercero, por lo que la diferencia frente a la estafa como delito derivado del estelionato solo se encontraría en la calidad de peligro abstracto para bienes individuales de las afectaciones a la fe pública. Para una explicación detallada del sentido de la distinción del derecho común entre engaño y falsedad a partir de adaptaciones de las figuras romanas del estelionato y del falsum y la forma en que la dogmática del siglo XIX trabajó esta distinción, véase la clásica exposición de BERNER (1986) pp. 594-595.

5 Al respecto, Mứler (2000) pp. 9-11 (en el derecho romano) y pp. 14-15 (en el derecho germánico). Sobre el fundamento de punición del perjurio en el derecho canónico y común, véase pp. 16 ss.

${ }^{6}$ Respecto al desarrollo del castigo de la mentira y de la desobediencia tras la abrogación de la tortura, Vormbaum (1987) pp. 83-91. 
generalmente independiente de la lesión de intereses individuales, las necesidades prácticas del sistema chileno han tendido a desnaturalizar a los delitos de falsedad (en particular, documental) y reconfigurarlos pragmáticamente bajo el primer modelo decimonónico de regulación amplia de la estafa. Pese a ello, la doctrina nacional de la Parte Especial no se ha preocupado especialmente de los delitos de falsedad ni ha parecido interesarse en los problemas dogmático-teóricos que la afectan ${ }^{7}$. Esto es particularmente claro cuando se compara el estado de la literatura chilena en la materia con otros países: mientras en el derecho comparado la atención entregada a estos es sumamente importante ${ }^{8}$, en el derecho nacional su tratamiento es más bien limitado. La magnitud del déficit puede, en ese sentido, ser fácilmente apreciada: este no solo se presenta respecto de una categoría de delitos que resulta en sí relevante y que posee peculiaridades dogmáticas únicas, sino que lo hace además respecto de una categoría con riesgo de seducción a la sobreexpansión en su aplicación y a su propia deformación.

El presente artículo pretende contribuir a comenzar a subsanar ese déficit. En tanto introducción a la dogmática de los delitos de falsedad, pretendo tematizar solo dos cosas:

- la posición sistemática de los delitos de falsedad en la Parte Especial (2), esto es, qué similitudes tiene la estructura de los delitos de falsedad con otras categorías y qué relaciones internas mantienen los tipos vinculados a la protección frente a la mentira; $y$

- ante todo, la cuestión central de la dogmática de los delitos de falsedad, a saber, el concepto de falsedad mismo (3).

El segundo punto será ilustrado solo a partir de una subcategoría de delitos, los delitos de declaración (falso testimonio y figuras relacionadas). Las razones de la decisión de centrarse en esos delitos, probablemente uno de los relacionados en menor medida con el efecto seductor de los delitos de falsedad, no son relativas a sus particularidades exclusivas. La subcategoría de delitos de declaración es, en cambio, aquella que se vincula en forma más directa con el concepto de "falsedad" de la categoría, esto es, se trata de los delitos que expresan la realización más pura del concepto general de "falsedad". Ello puede ser apre-

\footnotetext{
7 Una notable excepción la constituye el estudio histórico de Rojas, el que sin embargo solo tiene pretensiones históricas y más bien acotadas a falsedades documentales, véase RoJas (2012).

8 De acuerdo a una sentencia de Binding (1997) p. 108, la gran categoría de delitos de falsedad "puede ser designada como el más uniforme e interesante de los grandes grupos de delitos".

9 Que el concepto de "verdad" y "falsedad" que subyace al sistema penal se deja tematizar en su mejor forma a propósito del falso testimonio, es también compartido por Hilgendorf (1993) p. 547. En Alemania, a diferencia de la dogmática de fines del siglo XIX y principios del siglo XX -Binding, por ejemplo, reconocía en todos los delitos de falsedad una gran categoría-, la cuestión ha tendido, sin embargo, a especificarse: el concepto de falsedad es tematizado a propósito de cada subcategoría por separado. Esto, como se verá, tiene una explicación: la estructura relacional designada por el concepto de verdad o autenticidad varía en distintas categorías que forman parte de la gran categoría de delitos de falsedad. Esa variación no solo se explica por la redacción de los tipos, sino sobre todo por consideraciones teleológicas ligadas a las distintas categorías de delitos de falsedad. La especificación es, en ese sentido, correcta. Pero no reconocer la gran unidad que subyace a la categoría y que es designada precisamente por el concepto de falsedad en cuanto descripción de una relación, constituye una pérdida importante frente a la dogmática antigua.
} 
ciado directamente en el tipo mismo de falso testimonio. Con la reforma producida por la ley 20.074 en el año 2005, la acción típica pasó a ser explícitamente dependiente del concepto de verdad. Mientras antes se definía como "dar falso testimonio", la redacción actual define la acción como "faltar a la verdad en su declaración, peritaje o traducción" ${ }^{10}$. Esta explicitación no es más que un reconocimiento de una característica inherente al falso testimonio: la doctrina nacional, ya antes de la reforma de 2005, hacía constantemente referencia a la idea de verdad para definirlo y tematizarlo ${ }^{11}$. Pese a su particularidad funcional dada por su relación con la administración de justicia como bien jurídico, el falso testimonio constituye de esta forma una suerte de tipo ideal en la tematización del concepto de falsedad de los delitos de falsedad. La tematización del concepto general de falsedad puede, por ello, especificarse en el falso testimonio. A su vez, las diferencias en el concepto de falsedad que se dan en otras subcategorías se dejan entender mejor en relación con las variaciones que suponen frente al concepto puro de falsedad del falso testimonio. Esto es algo que tanto el sistema de delitos de falsedad, como el tratamiento del concepto de falsedad, ilustran de forma clara.

\section{LA POSICIÓN SISTEMÁTICA DE LOS DELITOS DE FALSEDAD}

\subsection{Delitos de falsedad y delitos De expresión}

En la dogmática moderna, los delitos de falsedad no tienden a ser tematizados como categoría. La razón de ello es fácil de advertir. La sistematización de la Parte Especial suele ser realizada exclusivamente en relación con la identificación de un bien jurídico protegido: la idea de categoría de delitos designa a un conjunto de delitos que conforma unidad por proteger un mismo objeto.

Las categorías de delitos son, de esta forma, clases funcionales. A causa de la utilización parcialmente excluyente de este criterio de clasificación, la dogmática penal ha tendido a separar por completo las distintas sub-categorías aquí presentadas de delitos de falsedad ya que entre ellas no parece haber coincidencia de "bien jurídico". Eso es evidente en la primera separación relevante, a saber, entre protección del patrimonio frente al engaño y el castigo directo de la producción de falsedad. Incluso el gran defensor de la unidad de la categoría de delitos de falsedad, Binding, consideraba que la agrupación de delitos de falsedad y delitos de engaño del derecho común, dada ante todo por la recepción del falsum, constituía "una unión innatural"12. Pero esa dificultad en el reconocimiento de objetos funcionales comunes también es aplicable a la distinción entre falsedades

\footnotetext{
10 Por cierto, la unificación de la descripción de la acción típica del testigo, perito e intérprete hace que el concepto de "faltar a la verdad" del Código Penal no sea unívoco. Esto es evidente en el caso del intérprete: el intérprete solo tiene una función procesal en la traducción, por lo que la norma de comportamiento no puede sino referirse a esa específica función y no, en cambio, a un concepto directo de falsedad. Por ello, la ilustración tendrá lugar solo en relación con el falso testimonio en sentido estricto, es decir, del testigo.

11 Por ejemplo véase Etcheberry (1998) p. 190; Garrido Montt (2000) p. 111 ("faltando a la verdad objetiva”). También las ediciones anteriores de Rodríguez y OsSANdón (2008), hacían referencia como hoy -p. 247 ("faltando a la verdad") - a la idea de verdad.

12 Binding (1997) p. 109.
} 
documentales genéricas, falso testimonio y falsificaciones específicas (por ejemplo de moneda). Mientras todavía Binding sostenía la existencia de unidad no solo estructural sino también funcional en buena parte de estos tipos, agrupando todo ello bajo la idea de la protección de valores probatorios ${ }^{13}$, la distinción entre protección de la administración de justicia, la fe pública/el valor del documento y otras categorías específicas, defendida, entre otros, por Franz v. Liszt, el gran rival de Binding, terminó con razón imponiéndose. En eso, la insistencia de Binding sobre la unidad de la categoría parece precisamente haberle jugado en contra a esa unidad: siendo difícilmente sostenible la unidad de bien jurídico de todos los delitos en cuestión, a menos que uno lo reconstruya con un grado excesivamente alto de abstracción, la pretensión de tratamiento conjunto de Binding podía ser fácilmente refutada sin hacerse cargo de la completamente convincente uniformidad estructural identificada, entre otros, por él. Por ello, en la identificación de un sistema se trata aquí de la identificación de estructuras compartidas y no, en cambio, del reconocimiento de funciones compartidas.

Considerados en relación con su estructura, los delitos de falsedad pueden ser presentados como una clase particular de delitos de expresión. Delitos de expresión en sentido amplio son aquellos delitos que requieren ser realizados con algún tipo de manifestación inmediatamente comunicativa, por oposición a los delitos materiales, respecto de los cuales el sentido de lo que se imputa depende de un mero hecho bruto. Ciertamente, hacer una distinción categórica entre delitos "expresivos" y delitos "no expresivos", en el sentido de no comunicativos, resulta en un sentido importante imposible: toda imputación de responsabilidad penal implica imputación de una acción como algo que porta a lo menos el sentido mínimo de desautorizar o contravenir una norma, es decir, a lo menos tiene el sentido objetivo otorgado por la misma norma. Pero a diferencia de los delitos puramente materiales, en los cuales el sentido de lo que se imputa es la pura desautorización de la norma de comportamiento cometida en las condiciones de imputación fijadas por la norma de sanción, la acción en los delitos de expresión es portadora de un sentido comunicativo autónomo; sin dar cuenta de ese sentido, ya la acción no es comprensible. Esto es, ya antes de ser tematizada por la norma en tanto esquema de determinación conceptual de sentido, la acción en los delitos de expresión tiene necesariamente algún tipo de pretensión comunicativa reconstruible por medio del lenguaje.

La pretensión comunicativa que se manifiesta en las acciones en que se imputan delitos de expresión no necesariamente requiere tener lugar por medio de un enunciado articulado por medio del lenguaje natural. Así, la injuria de hecho, típicamente posible de acuerdo a la definición de la injuria contenida en el artículo 416 del Código Penal, ciertamente constituye un delito de expresión. En ella, se castiga el haber expresado una forma de menosprecio respecto de otro, pese a que, si algún sentido tiene la distinción entre "de hecho" y lingüística, el menosprecio no puede haberse expresado con palabras. Sin embargo, incluso los delitos expresivos no realizados mediante el lenguaje necesitan ser produci-

13 Binding (1997) pp. 108 y ss. 
dos necesariamente mediantes actos que tengan pretensiones comunicativas que se dejen reformular lingüísticamente ${ }^{14}$.

Siendo la pretensión comunicativa de la acción determinante para el juicio de imputación en los delitos de expresión, estos deben ser tematizados y clasificados atendiendo principalmente al tipo de pretensión comunicativa que se entable. Dentro de la gran categoría de delitos de expresión, los delitos de falsedad precisamente adquieren especificidad en relación con este punto. En ellos se imputa alguna forma de disonancia entre comunicación y referencia; a ellos subyace necesariamente un incumplimiento de una pretensión de verdad bajo una reconstrucción determinada del sentido del acto expresivo.

\section{2.. LAS SUbCATEGORÍAS DE DELITOS DE FALSEDAD}

Los delitos de falsedad admiten ser sub-clasificados dependiendo de la imputación que se hace respecto de la pretensión comunicativa que necesariamente conllevan. Así, puede distinguirse entre (i) delitos de falsedad proposicional o de falsedad en sentido estricto, caracterizados por constituir directamente, y sin más, una forma de vulneración de una pretensión de verdad cuya no defraudación es exigida normativamente; (ii) delitos de falsificación, cuya estructura requiere de la representación falsa de la apariencia de cumplimiento por parte de un objeto determinado de ciertas características fijadas por otro objeto de referencia; (iii) delitos de imputación falsa, en los cuáles se castiga la falsa atribución de una propiedad determinada a un sujeto; y (iv) delitos de engaño, en los que, más allá de la producción de comunicación falsa, el tipo requiere la producción objetivamente idónea de una representación discordante (además de la eventual producción de un resultado típico adicional necesario a la consumación, como en el caso de la estafa). Las diferencias entre estas distintas sub-categorías pueden ser mejor comprendidas revisando lo que caracteriza en particular a cada una de estas.

\section{a) Delitos de falsedad proposicional: representación errada de la realidad lingüisticamente articulada}

En el esquema de clasificación de los delitos de falsedad, los delitos de falsedad propiamente tales o delitos de falsedad proposicional se caracterizan por constituir casos en que la imputación en principio se agota en la verificación de la enunciación de algo "falso". En

\footnotetext{
${ }_{14}$ El concepto de pretensión comunicativa aquí se toma en un sentido amplio y un tanto ambiguo. Ciertamente los delitos contra el honor y la honra tienen pretensiones comunicativas directas: expresan disminución de la estima por otro y solo cuando la acción puede ser reconstruida como teniendo ese sentido, puede ser posible la imputación penal. Mucho más claro es el caso del falso testimonio: este necesita articulación lingüística. Pero el concepto amplio de pretensión comunicativa incluye, a su vez, por ejemplo a la fabricación de símbolos o de instrumentos como la moneda, expresivas de valor. Por ello, distinguir entre delitos de expresión y delitos puramente materiales, como son los delitos contra la vida, los delitos contra la libertad, los delitos sexuales o los delitos contra la propiedad, no es conceptualmente simple. La violación probablemente tenga una pretensión comunicativa de desprecio, en los hechos, mucho más clara que la pretensión comunicativa de la fabricación de dinero. La diferencia es que puede no tenerlo: la violación puede no comunicar nada -de acuerdo al esquema de determinación de sentido constituido por la norma, basta con el acceso carnal mediado por coacción violenta para que el acto bruto tenga sentido normativo-, mientras que la fabricación de moneda necesariamente tiene que expresar ese valor para poder ser imputada.
} 
términos de la teoría de los actos de habla, el tipo de acto de habla mediante el cual pueden cometerse los delitos de falsedad propiamente tales corresponde exclusivamente a lo que Habermas denomina actos de habla constatativos, es decir actos de habla con contenido proposicional descriptivo y una oración subordinada afirmativa ${ }^{15}$, y en los cuales la pretensión de verdad que subyace a un acto de habla de este tipo falla, esto es, no se cumplen (de forma imputable al emisor) las condiciones de verdad del acto de habla realizado por este.

Los delitos de falsedad proposicional requieren, por ello, necesariamente articularse de forma lingüística y, visto desde la óptica pragmática, poder ser reconstruidos como actos de habla constatativos ${ }^{16}$. A diferencia de otras formas de delitos con componentes de falsedad, ellos no admiten su consumación por un medio distinto del lenguaje. Uno no puede pensar en falso testimonio sin determinación lingüística y difícilmente puede hacerse respecto de los delitos de falsedad ideológica.

Así, aquello que determina la especificidad de los delitos de falsedad proposicional o propiamente tales dentro la gran categoría de delitos de falsedad es que solo en ellos el término falsedad se utiliza de forma estricta (no verdad), ya que solo ellos requieren de la producción directa de una declaración que pueda ser reconstruida como discordante con su objeto. Como se verá, el contenido de injusto de estos delitos -en lo esencial, la producción de falsedad- se deja especificar mediante la estructura relacional de falta de correspondencia entre declaración y objeto de la declaración ("realidad”). En los demás delitos de falsedad, la estructura relacional también tiene lugar, pero los objetos de la relación varían.

En el derecho penal chileno, los casos más claros de delitos de falsedad en sentido estricto son el falso testimonio (artículo 206 del Código Penal) y las hipótesis más claras de falsedades ideológicas punibles de los artículos 193 número 2, 3 y 4 y 197 del Código Penal, aunque algunos casos de falsificaciones de documentos públicos son, en realidad, delitos de falsedad en sentido estricto (piénsese, por ejemplo, en la certificación falsa de enfermedad del artículo 202 del Código Penal). El análisis de la estructura específica de estos delitos, y de la forma en que se concretan como delitos de falsedad proposicional, es competencia de su propia dogmática. Pese a ello, la sección 3 pretende dar cuenta de la estructura general de esta subcategoría a partir del análisis del concepto de "faltar a la verdad" del artículo 206 del Código Penal.

\section{b) Delitos de falsificación}

A diferencia de los delitos de falsedad, los delitos de falsificación no necesitan de comisión mediante el lenguaje natural. Aunque puede ser el caso, su contenido de manifestación puede expresarse por otros medios, tales como símbolos (marcas, dinero, sellos, incluso objetos brutos). Esta es la primera diferencia con los delitos de falsedad propiamente tales.

En un segundo aspecto, los delitos de falsificación son un caso especial de los delitos de falsedad. Mientras que, como se verá, los delitos de falsedad en sentido estricto funcionan sobre la ficción de la producción de una comparación entre declaración y hecho

\footnotetext{
15 Al respecto, véase Habermas (1989) pp. 88 y ss.

16 Similar Binding (1997) pp. 112 ss., mediante la distinción entre declaración probatorio y signo probatorio. En los casos de declaración -delitos de falsedad en sentido estricto-, la estructuración lingüística es necesaria.
} 
-pese a que, en realidad, se trata de comparación entre declaración juzgada como falsa y una declaración alternativa considerada verdadera-, en los delitos de falsificación hay una comparación entre la apariencia de algo (origen con potestades de producción de moneda, sustancia, valor, símbolo) y su falta de correspondencia con el objeto aparentado o con las condiciones bajo las cuáles aparece producido (por ejemplo, aparentando ser de autoría de quien tiene potestades para hacer uso de un sello oficial). La estructura de la falsificación también es, de esta forma, una estructura relacional, pero los objetos de la relación no son declaración y realidad, sino apariencia y objeto de referencia de la apariencia. Esto puede ser ejemplificado en el caso más simple, el de la falsificación de moneda de los artículos 162 y siguientes del Código Penal. La falsificación de moneda implica la comparación entre un objeto producido (la moneda falsa), al cual se le atribuye el sentido comunicativo de manifestar el cumplimiento de las condiciones para ser expresiva de dinero, y su objeto de referencia, el dinero válidamente emitido, habiendo incumplimiento de las condiciones de producción del objeto de la referencia (u objeto aparentado). Esta discordancia entre apariencia y objeto de referencia de la apariencia también admite reconstruirse como relación entre declaración (aquí: tácita) y realidad: al sujeto se le imputa la afirmación de que el objeto cumplía con determinadas características que no cumple. Pero a diferencia de los delitos de falsedad en sentido estricto, la dependencia de la comparación con características del objeto hace que los delitos de falsificación sean determinados, esto es, la ley necesita especificar ciertos objetos que no pueden ser producidos sino cumpliendo ciertas condiciones (moneda en los artículos 162 y siguientes, documento público en alguna de las hipótesis de los artículos 193 y 194 del Código Penal).

Al igual que los delitos de falsedad proposicional, la consumación de las falsificaciones tiende a no requerir de la producción de representaciones falsas ${ }^{17}$. Por eso, al igual que las falsedades documentales de contenido, pueden entenderse correctamente como delitos de peligro abstracto (de engaño) vinculados a la protección del patrimonio: no necesitan ni representación del destinatario ni afectación del patrimonio o de algún otro interés protegido penalmente ${ }^{18}$. Para su consumación, a diferencia del falso testimonio y de la misma forma que las falsedades documentales, basta la producción de la apariencia. En los otros casos, se necesita o bien la comprensión del mensaje por el destinatario (falso testimonio, delitos de imputación) o bien incluso la generación de un cierto efecto en el destinatario (falsa representación en los delitos de engaño).

\section{c) Delitos de imputación (falsa)}

La categoría de los delitos de imputación también integra parcialmente a la gran categoría de delitos de falsedad. No todos los delitos de imputación son, sin embargo, delitos de falsedad en sentido amplio.

\footnotetext{
17 Véase Kern (1965) pp. 50 y ss.

18 Esto es exactamente lo mismo que decir que los delitos de falsificación específica tienen un destinatario indeterminado y no necesitan de víctima, mientras que los delitos de producción de falsedad tienden a limitar, al menos, el sujeto activo. Véase JaKobs (2000) pp. 8-10.
} 
En los delitos de imputación, se atribuye propiedad sobre algo a una persona. El objeto sobre el que se atribuye propiedad se ve especificado por el tipo en cuestión. En el derecho penal chileno, los casos más claros de delitos de imputación son la injuria (artículos 416 y siguientes del Código Penal) y la calumnia (artículos 412 y siguientes del Código Penal), en los que respectivamente se imputa una característica o acción deshonrosa o la comisión de un delito. En todos estos casos, el objetivo de la comunicación que constituye la acción típica es dar cuenta de esa relación de propiedad sobre lo imputado. En ese sentido, el acto de habla en cuestión debe servir a lo menos para manifestar una pretensión de ver$\mathrm{dad}^{19}$, aunque pueda requerir de pretensiones pragmáticas ulteriores.

No todos los delitos de imputación son delitos de falsedad. Algunas imputaciones verdaderas pueden ser punibles conforme a las reglas de la injuria, la que excluye generalmente la exceptio veritatis en el artículo 420 del Código Penal. En el caso de la calumnia, el delito de imputación es necesariamente un delito de imputación falsa, ya que la falta de verdad es un requisito del tipo y el ordenamiento jurídico le asigna además a la demostración de la verdad el estatus de constituir una excepción especial en el artículo 415 del Código Penal ${ }^{20}$. Por ello, la calumnia se constituye no solo como un delito de falsedad en sentido amplio, sino también en sentido estricto: constituye necesariamente una vulneración de una pretensión de verdad en sentido estricto en un acto de habla aseverativo ${ }^{21}$. Pese a ello, el mayor peso que tiene la especificidad de la imputación hace conveniente distinguirla de los delitos de falsedad en sentido estricto y clasificarla como un delito de imputación.

Al igual que los delitos de engaño, y a diferencia de los delitos de falsedad, los delitos de imputación solo requieren de comunicación, no necesariamente de comunicación lingüísticamente mediada. Esto no se aplica a las formas de calumnia, las que en tanto delitos de falsedad en sentido estricto requieren de formulación lingüística, pero sí a la injuria a causa de la punibilidad expresa de la injuria de hecho ("acción ejecutada" por oposición a “expresión proferida” en el artículo 416 del Código Penal).

Asimismo, a diferencia de los delitos de falsificación, los delitos de imputación requieren de comprensión ${ }^{22}$. Ya la regulación como delitos de acción penal privada (y el requisito de ser conocida por autoridades en el caso de la imputación calumniosa) da cuenta del hecho que los delitos de imputación requieren de comprensión del destinatario para ser punibles. Esto nuevamente los asimila a los delitos de falsedad en sentido estricto si se sigue el criterio de la comprensión como determinante de la consumación.

\section{d) Delitos de engaño}

Los delitos de engaño son formas de delitos de falsedad, en los cuales la expresión juega el rol de permitir la representación falsa de algo por parte del destinatario de la comunicación, de forma tal de producir otro resultado gracias a esa representación falsa.

\footnotetext{
19 Fundamental véase Mañalich (2005) pp. 206 y ss.

20 Mañalich (2005) pp. 224 y ss.

21 Véase Mañalich (2005) pp. 224-226.

22 Véase Kern (1965) pp. 54 y 55.
} 
Frente a los delitos de falsedad, los delitos de engaño se diferencian en al menos tres puntos:

(i) No se encuentran necesariamente articulados de forma lingüística. Aunque el engaño supone comunicación, este puede tener lugar mediante comunicación no lingüística e incluso, se afirma (controvertidamente dada su supuesta calidad de delitos de medios comisivos calificados) por omisión ${ }^{23}$;

(ii) Los delitos de engaño no son delitos de producción de falsedad, sino de producción de representación falsa. Por ello, lo que en ellos se imputa no es la producción de una comunicación falsa, es decir, no se atiende a la perspectiva objetiva de interpretación del sentido de la comunicación como falsa (en términos metafóricos: discordante con la realidad), sino a la idoneidad para producir una representación falsa en el destinatario. Dicho de otra forma: puede engañarse con la verdad y ser ello imputable; $y$

(iii) A diferencia de los delitos de falsedad, los delitos de engaño presuponen conceptualmente para su consumación no solo la expresión, ni siquiera solo la comprensión por parte del interlocutor, sino la producción de una representación falsa mediada por una comprensión anterior del acto de comunicación. Esto altera el criterio de determinación de la consumación del tipo: mientras en los delitos de falsedad en sentido estricto los dos criterios que pueden determinar la consumación son la emisión y la comprensión, en los delitos de engaño a lo menos se requiere de un paso ulterior dado por la producción de la representación falsa (en el caso de la estafa, como delito contra el patrimonio, ella requiere además de la irrogación de perjuicio) ${ }^{24}$.

\section{EL CONCEPTO DE JURÍDICO PENAL DE FALSEDAD}

\subsection{Las dos anomalías del CONCEPTO DE FALSEDAD: DEPENDENCia METAFÍsica y APARENTE ANOMALÍA INSTITUCIONAL}

La clasificación genérica presentada respecto de las formas en las cuales la falsedad puede ser típicamente relevante permite reconocer el lugar específico que le corresponde estructuralmente a los delitos de falsedad en el proceso y, en especial, al falso testimonio.

En su estructura de imputación, los delitos de declaración falsas son formas prácticamente puras de delitos de falsedad en sentido estricto. Al igual que los demás delitos de falsedad en sentido estricto, estos delitos tienen, como resulta obvio, una dependencia conceptual directa con el concepto de "falsedad". Esta dependencia general de la categoría no es puramente teórica. A lo largo del Libro II del Código Penal, el concepto de falsedad es

\footnotetext{
23 Ya antes Kern (1967) pp. 23 y 24, ponía en duda el carácter de delito de expresión de la estafa precisamente a propósito de la posibilidad de imputar estafa por omisión, esto es, en sus términos, engaño en el cual falta el contenido de manifestación conceptualmente necesario a todo delito de expresión. Bajo sus presupuestos conceptuales, solo dos conclusiones lógicas eran aceptables: o bien el engaño sin manifestación no podía constituir ni siquiera estafa tentada, ya que el principio de ejecución se daría solo con la manifestación, o bien era necesario aceptar que la estafa y otros delitos de engaño pudieran constituir delitos puramente materiales.

24 Sobre la exigencia de la producción de un resultado comunicativo como requisito de consumación del engaño típico, KerN (1967) pp. 46 y 60 y ss.
} 
directamente utilizado en más de 30 ocasiones. Probablemente, se trata del concepto normativo de mayor extensión geográfica en todo la Parte Especial del derecho penal chileno. A su vez, el concepto de verdad define directamente, como ya fue señalado, el contenido de injusto del falso testimonio en el artículo 206 del Código Penal.

La dependencia semántica de los delitos de falsedad de los conceptos indeterminados de falsedad y verdad es conflictiva: en la determinación de lo que constituye falsedad -del "faltar a la verdad" del artículo 206 del Código Penal-, tenemos una dependencia que parece insalvable respecto de conceptos y nociones aparentemente metafísicas que resultan, por ello, conflictivas ${ }^{25}$. Las aporías que manifiesta el concepto de falsedad en sentido estricto en el sistema penal le afectan con particular fuerza a los delitos de declaración por su condición de manifestación paradigmática de delito de falsedad.

Lo conflictiva que resulta esta dependencia con la noción de verdad puede ser percibido inmediatamente al intentar representarse de forma simple el contenido del concepto de falsedad en el falso testimonio. Una representación intuitiva más o menos correcta del concepto de falsedad consiste en sostener que este designa una relación de no correspondencia entre la declaración y la realidad ${ }^{26}$. Aunque esta formulación no puede ser de entrada criticada en su consistencia interna, ella es desde un inicio conflictiva por centrar todo su poder explicativo en un concepto igualmente conflictivo que el de verdad: el concepto de realidad ${ }^{27}$. Alternativamente, uno podría intentar definir negativamente a un enunciado falso como un enunciado no verdadero o, con lógica sustantiva, sosteniendo que la falsedad es la ausencia de verdad. Esta estrategia conceptual efectivamente no puede ser incorrecta, pero es literalmente inexpresiva: ciertamente es correcto sostener que falso es lo que no es verdadero, pero al no ser más que una mera tautología, pese a la corrección lógica de ese enunciado, la determinación de su sentido es dependiente, de nuevo, de la determinación del contenido del concepto de verdad. Y esto demuestra directamente que en la determinación de lo que constituye falsedad aparece un vínculo conceptual prácticamente insalvable con al menos dos conceptos de raíz metafísica conflictiva como son "realidad" y "verdad"28.

\footnotetext{
25 También Rojas (2012) p. 553, identifica y critica un cierto descrédito del concepto de verdad por la falsa asunción de un carácter metafísico.

26 Que la teoría de la correspondencia reproduce intuiciones cotidianas sobre la idea de verdad, es algo generalmente asumido. Así también, haciendo referencia a una supuesta utilización implícita o explícita por parte de la dogmática jurídica, Hilgendorf (1993) pp. 549-550; Paulus (1987) p. 436; Maurach/ Schroeder/Marwald (2005) $\$ 75 \mathrm{Nm}$. 14; SteIn (2008) pp. 2-3. Esa asunción táctica también aparece entre nosotros. Al dar cuenta del contenido de injusto del falso testimonio, por ejemplo Rodríguez y OsSANDÓN (2008) p. 251, lo definen como "discrepancia entre la declaración y la realidad de los hechos". Lo notable en la definición de Rodríguez y Ossandón es que precisamente manifiestan la necesidad de hacer referencia al conflictivo concepto de realidad.

$27 \mathrm{Al}$ respecto, Infra.

28 Por cierto, no todos los tipos penales incluidos en la categoría amplia de delitos de falsedad parecen verse aquejados por una necesidad de recurso a este tipo de conceptos metafísicos complejos. No sucede en lo que hemos denominado "falsificaciones", en las cuales antes que una representación falsa de la realidad hay atribución de potestades que no se tienen (típicamente en el caso de la fabricación de monedas), designación de materiales o sustancias como algo que no son (por ejemplo, con oro o plata), firmas hechas suplantando identidades que no se tienen o simulando sellos respecto de los cuales no se tienen facultades de uso. Aunque profundamente todos estos tipos de casos de falsificaciones tienen una dependencia con las aporías descritas,
} 
Esta dependencia de conceptos de raíz metafísica se acentúa precisamente por tratarse, en el caso de la verdad, de uno de los conceptos centrales de la metafísica y, en general, de la filosofía. Esto es, parte importante de las aporías conceptuales vinculadas a los delitos de falsedad derivan del hecho que se encuentran insertos en un área en que la filosofía tiene una pretensión particularmente fuerte de propiedad, al punto que se trata prácticamente de su concepto central. "Bibliotecas completas han sido escritas al respecto" 29 . Ese profundo enraizamiento que tiene la idea de verdad en la filosofía ha marcado, por lo mismo, las aporías a las que constantemente reenvía el concepto de verdad en el derecho. Es, en parte, esa carga histórica conflictiva la que determina las complicaciones del estudio dogmático de los delitos de falsedad. A causa de esta derivación del problema de lo conflictivo que resulta en sí el concepto de verdad en la filosofía, puede hablarse de una aporía conceptual derivada.

Existe, además, un segundo aspecto conflictivo en los delitos de falsedad. Más allá de la aporía conceptual derivada, los delitos de falsedad parecen ser institucionalmente anómalos. Sea cual sea el concepto de verdad que se maneje, el tipo de verificación cognitiva de hechos que se manifiesta en la argumentación jurídica y en el proceso es particularmente débil. A diferencia de discursos científicos y otros ámbitos en los cuales las afirmaciones de hecho deben ser justificadas en condiciones orientadas a su mejor verificación en abstracto posible, en el proceso esa justificación tiene lugar en condiciones que impiden por regla general una reproducción directa de lo que se quiere verificar o de los presupuestos fácticos que permiten hacer inferencias de alta probabilidad: puede ser que el proceso se oriente a la mejor verificación concretamente posible de los hechos a los que se refiere, pero ese mejor posible concreto es, en abstracto, sumamente deficiente ${ }^{30}$. Los enunciados de hechos que deben ser justificados por los jueces deben serlo por referencia a la prueba, la que sobre todo en materia penal tiene más bien la forma de huellas indirectas de cuestiones que tuvieron lugar en el pasado, sin permitir percepción directa de los hechos respecto de los cuales se aplican las normas. Por eso, el tipo de argumentos que son utilizados para justificar las premisas fácticas de la argumentación jurídica -la valoración de la prueba- es epistémicamente débil. Esto es una característica general del razonamiento jurídico y que da cuenta de cierta debilidad estructural de la administración de justicia. Esta debilidad estructural, prácticamente inherente a nuestras instituciones, parece incrementarse en los delitos de falsedad en sentido estricto. En ellos, no solo son objeto de justificación enunciados fácticos relativos a los hechos, sino que el objeto directo de imputación es la falta de correspondencia entre un enunciado y la "realidad" que le corresponde. Es decir, el objeto de prueba es directamente la verdad de una afirmación. Y aquí parece revelarse una falencia epistémica

uno puede representarse su contenido de injusto en la práctica sin tener que expresar perplejidades al tratarlo. Eso sucede por ejemplo en el caso del oro u otras sustancias falsificadas. Aquí la comparación es mundomundo: la pregunta es si la sustancia presentada como oro es en realidad oro. Debido a que el objeto de referencia tiene una constitución física fácilmente identificable, la cuestión de la comparación de los objetos es trivial. Esto es precisamente lo que hace mucho más interesante el análisis dogmático de los delitos de falsedad en sentido estricto y, en particular, al falso testimonio.

29 Hilgendorf (1993) p. 547. Véase, similar, Kaufmann (1992) pp. 122-123.

30 La asunción que el proceso representa la forma más eficaz posible de reconstruir hechos pasados para la realización de un juicio es, por cierto, poco convincente. El proceso, y aquí sobre todo el proceso penal, tiene pretensiones de disciplina del Estado -y controvertidamente de privados- que limitan precisamente su eficacia. 
adicional que daría cuenta de una anomalía institucional relevante: el objeto de imputación en los delitos de falsedad es directamente el faltar a la verdad, lo que debe ser justificado en condiciones que no son adecuadas para la justificación de la verdad y, por lo tanto, tampoco para la justificación de la ausencia de verdad (falsedad) ${ }^{31}$. Esto precisamente ha llevado a parte de la doctrina a manifestar cierto escepticismo a su respecto; la protección de la verdad objetiva sería irrealizable, con lo que uno podría concluir que "pocos grupos de delitos son tan dudosos en sus fundamentos como los delitos de declaración” ${ }^{32}$.

En lo que sigue, pretendo tematizar el tipo de concepto de verdad que subyace a los delitos de falsedad en una comprensión correcta de estos y, a partir de ello, demostrar la ausencia de anomalías institucionales específicas en estos. Es decir, pretendo sostener que la correcta tematización de la primera de las aporías descritas (la aporía conceptual derivada) permite inmediatamente entender por qué no hay anomalía institucional propia de estos. Como se verá, ello no permite solucionar del todo los problemas dogmáticos que afectan al falso testimonio -las llamadas teorías de la falsedad son, contra lo que se cree, al menos parcialmente independiente de los problemas vinculados al concepto jurídico de verdad y, con ello, a las teorías filosóficas de la verdad-, pero sí permite posicionar esta discusión específica y mostrar que ella, en realidad, no hace más que reproducir las especificaciones del concepto de verdad que subyacen a todo delito de falsedad.

\subsection{VERDAD Y FALSEDAD}

En la discusión filosófica respecto al concepto de verdad, la teoría de la verdad que intuitivamente resulta más verosímil, y que por ello tiene un mayor grado de aceptación, es la así llamada teoría de la correspondencia ${ }^{33}$. Aunque de particular interés durante el siglo $\mathrm{XX}$, en su forma clásica la teoría de la correspondencia suele ser reconducida a la formulación algo tautológica de Aristóteles ${ }^{34}$, y a la mucho más directa formulación de Tomás de Aquino como adecuatio rei intellectum.

La teoría de la correspondencia básicamente sostiene que la verdad es una relación entre "algo" -cuyos dos grandes candidatos son los pensamientos o estados mentales, en su forma clásica, y las expresiones lingüísticas, en su forma más bien ligada al giro lin-

\footnotetext{
31 Esto puede parecer una consideración trivial, pero tienden a ser utilizado como un argumento relevante para criticar a las llamadas teorías objetivas de la falsedad (sobre este concepto, véase Infra.): si falsedad se define como falta de correspondencia con la realidad objetiva, entonces todo enunciado del testigo que vaya más allá de afirmar o negar sería por definición falso, con lo que la teoría ni siquiera tendría poder de diferenciación de enunciados falsos y verdaderos de un testigo. Así, con referencias ulteriores, MülLER (2000) pp. 83-84. El argumento exagera, por cierto, los problemas ligados al concepto de verdad (¿por qué habría de ser necesariamente falso?), pero al mismo tiempo se desentiende del hecho que la cuestión afecta, a su vez, al enunciado del juez respecto del cual la declaración es considerada falsa: este, a su vez, solo es tenido por verdadero; no requiere (ni puede requerir) ser verdadero.

32 SCHMidhäUSER (1961) p. 207.

33 Con mayor detalle, véase Kaufmann (1992) pp. 120 y ss.; Hilgendorf (1993) pp. 549-550; SCruton (1999) pp. 100-102; Habermas (1989) pp. 95 y ss.

34 Al respecto véase, SCRUTON (1999) p. 100
} 
güístico ${ }^{35}$ - y otro algo que no tiene entidad lingüística o dependiente del sujeto sino una sustancia independiente, esto es, algo que no se ve afectado por el sujeto ${ }^{36}$. La teoría de la correspondencia presupone que la verdad designa una relación entre sujeto (en su versión clásica y bajo el paradigma de la filosofía de la conciencia), o algo que al menos depende del sujeto (en su versión contemporánea: formulaciones lingüísticas), y objetos independientes. Cuando hay igualdad, o equivalencia -correspondencia-, entre los dos pares de la relación, entonces hay verdad. Bajo el paradigma de la filosofía analítica, debido a que toda cuestión espiritual o racional es en realidad una formulación lingüística, la teoría de la correspondencia básicamente sostiene que una afirmación es verdadera cuando aquello que se afirma corresponde a la realidad.

El que la teoría de la correspondencia reciba particular atención en un estudio sobre el concepto de verdad en los delitos de falsedad, no es algo que pueda sorprender. La teoría de la correspondencia (moderna) parte de la base conceptual de que la verdad (y en ese sentido la falsedad) designa una forma de relación entre enunciados lingüísticos y hechos, mientras la estructura típica de los delitos de falsedad también parece requerir de una comparación entre los mismos pares, a saber, entre un enunciado o conjunto de enunciados, el que sirve como objeto de imputación, y la realidad a la que se refieren y con la que estos deben ser comparados, la que cuenta como determinante de las condiciones de verdad del enunciado. Esto es precisamente lo que hace necesario presentar una crítica y una demostración de los límites de la teoría de la correspondencia. Ya que el tratamiento intuitivo de los delitos de falsedad reenvía a la idea de correspondencia ${ }^{37}$, solamente por medio de una crítica a esta puede verificarse la presencia o ausencia de anomalías institucionales en estos.

Pese a que puede parecer que la teoría de la correspondencia no hace sino expresar una obviedad, sus pretensiones como teoría de la verdad son en realidad particularmente ambiciosas. La teoría de la correspondencia pretende no solo designar lo que caracteriza a un enunciado verdadero, sino también dar cuenta de las condiciones de justificación (o adquisición) del conocimiento. Esto es, la teoría de la correspondencia es sobre todo una teoría del conocimiento. Para ello, para poder dar cuenta de su contenido epistemológico expresivo, la teoría de la correspondencia asume tres presupuestos básicos: (i) la idea que compara dos elementos disímiles (palabra y mundo/realidad, o pensamiento y mundo/ realidad): precisamente por ello permite la existencia de enunciados sintéticos y no solo enunciados analíticos; (ii) la pretensión de que ambos elementos pueden ser comparados, es decir que pese a su disimilitud ontológica tienen formas de reducción a denominadores comunes que permiten hacer el ejercicio de comparación; y (iii) que ambos lados de la ecuación pueden ser conocidos directamente de alguna forma.

En la filosofía contemporánea las críticas centrales a la teoría de la correspondencia provienen básicamente de dos o tres tipos de argumentos, todos los cuales se centran en

\footnotetext{
35 Respecto a los candidatos analíticos para ser portadores de verdad (enunciados, normas, estados mentales, etc.), véase solo Hilgendorf (1993) p. 549. A diferencias de los ancestros de las teorías de la correspondencia, en la filosofía moderna la posibilidad de considerar que estados mentales o espirituales son portadores de verdad, ya prácticamente no es sostenida.

36 Véase Scruton (1999) pp. 98-99.

37 Véase nota 26.
} 
atacar sus presupuestos anteriormente resumidos. Así se sostiene, en primer lugar que, dada la mediación lingüística en la comprensión del mundo, la teoría de la correspondencia compararía objetos iguales -lenguaje y lenguaje- y, por lo mismo, no sería interesante. En segundo lugar, los críticos actuales e históricos de la teoría de la correspondencia sostienen que esta sería circular ya sea por comparar objetos iguales, o por hacer uso de categorías que definen mediante conceptos equivalentes a los que se busca definir. Finalmente, se suele sostener que existe una supuesta imposibilidad de acceder a la realidad en tanto tal. El mundo desnudo de nuestra propia subjetividad, en los términos de la filosofía del conocimiento postkantiana, o, en una formulación postgiro lingüístico, el mundo despojado de nuestra comprensión común determinada por el habla, no sería accesible, lo que pondría en jaque la posibilidad de cumplimiento del tercero de los presupuestos de la teoría de la correspondencia y en el cual se juega sobre todo su capacidad de rendimiento epistémico.

En todos los casos las críticas se centran en las aporías conceptuales a las que necesariamente lleva la pretensión de definir aquello que se compara con el lenguaje o pensamiento, es decir, aquello que define las condiciones de verdad de los portadores de verdad (enunciados, afirmaciones, etc.). Bajo la formulación tradicional, la crítica se centra en la posibilidad de rendimiento del concepto de "realidad" y, en general, de todo concepto que describa las condiciones de verdad ${ }^{38}$. La teoría de la correspondencia necesita poder comparar lo subjetivo, el pensamiento o la expresión lingüística, con la realidad objetiva que tiene lugar con independencia del pensamiento, que no se ve afectada por este y que aunque no existiera el pensamiento, ella seguiría teniendo lugar exactamente de la misma forma. Esta dependencia tradicional de la teoría de la correspondencia con la noción de realidad es la que resulta problemática. Decimos que una expresión o pensamiento es verdadero si tiene lugar en la realidad. Y, sin embargo, si tuviéramos que buscar definir el concepto de realidad, llegaríamos casi necesariamente a la idea de que la realidad se encuentra compuesta por el conjunto de cosas verdaderas. Es decir, el concepto de realidad no agregaría nada a lo ya contenido directamente en el concepto de verdad: decir que un enunciado expresa verdad si puede ser reconducido al conjunto de estados de cosas que son verdad constituye una tautología básica. Nadie menos que Kant, el que a su vez sostenía un concepto de verdad como correspondencia ${ }^{39}$, expresó de forma sumamente elegante esta crítica en la Introducción de la Lógica de Jäsche: "con esta aclaración de la verdad uno se comporta de la misma forma que quien declara algo ante un tribunal y se remite a un testigo al que nadie conoce, pero al que quiere hacer creíble al señalar que el sujeto, al que hace referencia, sería un hombre honorable" ${ }^{40}$. Notable en la crítica kantiana es no solo su capacidad de mostrar la falta de capacidad de rendimiento que parece tener superficialmente el concepto de verdad. La ilustración de la crítica por comparación con un testimonio muestra cuán evidente parece ser la asunción de que el concepto de falsedad del falso testimonio se relaciona con

\footnotetext{
38 Véase Scruton (1999) pp. 100-102 y Habermas (1989) pp. 96-97; Habermas (2004) pp. 246 y ss. Por referencia a Habermas, véase similar KaUfmann (1992) p. 121.

39 Así, por ejemplo, en la Crítica de la Razón Pura (A 58, B 82): "Qué es la verdad? La aclaración conceptual de la verdad, en el sentido que ella es la correspondencia del conocimiento con su objeto, es aquí asumida y presupuesta”. KANT (1974) p. 102.

40 Kant (1800) p. 70.
} 
las teorías de la verdad; la asunción no funciona aquí desde la dogmática hacia la filosofía, sino también al revés.

El reenvío constante a la idea de realidad que parece encontrarse en las teorías de la correspondencia hace que tengan una primera razón de circularidad y tautología. Definen a la verdad en relación con la verdad. La noción de realidad parece ser tan dependiente de la noción de verdad para poder ser definida que difícilmente puede servir para su propia conceptualización.

Más allá de la circularidad y redundancia que parece manifestar el concepto de realidad, es difícil dudar, sin embargo, de la existencia de un mundo objetivo que tiene lugar con independencia de lo que creamos respecto de este. La duda de la filosofía moderna a este respecto -planteada en su forma más brutal en la segunda meditación metafísica como duda respecto a la propia corporalidad y a la corrección de enunciados tautológicamente verdaderos como las operaciones aritméticas ${ }^{41}$ - no puede, por cierto, ser comprendida como una duda real sobre la existencia del mundo objetivo; entendida así, es una duda sin sentido. Que ese mundo objetivo se deje reconstruir por el sujeto o por la comunidad de forma categóricamente distinta a su descripción, es algo que, sin embargo, no puede ser asumido con sentido ${ }^{42}$. Ello influye sobre la primera premisa que necesita la teoría lingüística de la correspondencia para no caer en la circularidad que ya fue mostrada, a saber, poder trazar la diferencia categórica entre lenguaje y realidad, pese a que pueda asumirse que esa diferencia existe. En otras palabras, si la comprensión del mundo objetivo se ve ineluctablemente mediada por el lenguaje, al comparar los enunciados con el mundo para determinar su verdad en realidad comparo lenguaje con lenguaje ${ }^{43}$. Debido a que la producción de esa diferencia no sería posible desde el momento en que toda forma de comunicación tiene que ser expresada mediante el lenguaje, esta premisa tampoco se cumpliría.

Las debilidades que subyacen a la teoría de la correspondencia tienden a producir en la dogmática la tentación de recurrir a sus teorías rivales ${ }^{44}$. Si, en realidad, estamos equivocados al asumir una comprensión de la verdad como correspondencia, los problemas relativos al concepto de verdad en la dogmática penal podrían ser solucionados con teorías no sujetas a esas críticas. Esa tentación es, sin embargo, producto de una ilusión dada por la pretensión de utilizar directamente (esto es: ingenuamente) la discusión filosófica para solucionar una discusión jurídica. Creer que el poder de convicción de las críticas efectuadas por las teorías rivales afecta al concepto penal de falsedad constituye un error por manejo incorrecto de las relaciones entre dogmática y filosofía. Aunque los problemas que afectan a las teorías de la correspondencia son ante todo, si se quiere, metafísicos, la cuestión crucial

\footnotetext{
41 Sobre la reconstrucción de la duda de la segunda meditación metafísica como contradicción performativa, véase solo Habermas (2004) pp. 243-246.

42 Véase similar Habermas (2004) pp. 246-247; Kaufmann (1992) pp. 121-122.

43 Al respecto véase, SCRUTON (1999) pp. 101-102. Esa conclusión que puede resultar dramáticamente decepcionante en la filosofía para la teoría de la correspondencia es, en el contexto de los delitos de falsedad, completamente obvia. Véase Infra.

44 Así tendencialmente Kaufmann (1992) pp. 125 y ss., quien pese a ello termina defendiendo una versión "alterada" de la teoría de la correspondencia. Véase también KARGL (2003) pp. 796 y ss., pretende aplicar indirectamente la teoría consensual de la verdad.
} 
que se juega en las teorías de la verdad es su capacidad de rendimiento epistemológico y el tipo de concepto de "conocimiento" al que llevan. Bajo la teoría de la correspondencia, conocimiento es correspondencia; si se da la correspondencia entre el enunciado y la realidad, entonces hay una relación de verdad inmutable. Esa premisa puede ser asumida como ingenua por su construcción del concepto de realidad como algo dado. Pero esa ingenuidad no es algo que afecte al mundo jurídico, donde contextualmente estamos obligados a convivir con falibilidad. Aquello que consideramos jurídicamente "verdadero" -o probado- no es asumido prácticamente por nadie como parte de una relación inmutable, sino como un enunciado simplemente justificado por referencia a reglas de valoración. No es razonable asumir que juristas y legos creen de forma injustificablemente ingenua que todo enunciado probado en juicio es necesariamente verdadero; al contrario, la enorme falibilidad en el conocimiento de los hechos por parte de la administración de justicia es algo que la sociedad conoce y resiente.

A causa de nuestra aceptación necesaria de la condición de que la "verdad" procesal solo puede ser tratada como mera idea regulativa, su realización jurídica puede antes servir de ejemplo a la filosofía que al revés. Esto puede ilustrarse, por ejemplo, en las variaciones de una de las teorías de la verdad contemporáneas más influyentes: la teoría pragmáticaconsensual de la verdad de Jürgen Habermas. Como se verá, Habermas ha terminado por poner la distinción entre verdad y "enunciado justificado por prueba", propia de todo discurso -incluyendo el de los enunciados referidos a los hechos de la administración de justicia-, en el centro de su propia concepción discursiva de la verdad.

Como es trivialmente conocido, la idea original básica de la teoría habermasiana de la verdad asume una consideración pragmática y analítica de esta. La idea es simple: en nuestras formas de utilización universales de lenguaje, una de las pretensiones que se suelen plantear con el lenguaje en tanto acto de habla -es decir en su dimensión pragmática (en aquello que se hace con el lenguaje) - es la pretensión de verdad. La pretensión de verdad es un tipo de pretensión de validez que es propia de los enunciados constatativos, es decir, de enunciados que junto con describir, afirman la verdad de lo descrito en su dimensión pragmática ("oración subordinada”); la expresión implicaría de esta forma un reclamo de que la descripción propia de la oración principal debe ser interiorizada y compartida por los interlocutores. El que los actos de habla constatativos tengan esta forma tendría, a lo menos, una explicación funcional: ella sirve de base cognitiva a la coordinación de la acción en determinadas prácticas que requieren de esa base ${ }^{45}$.

Es, sin embargo, funcional y cognitivamente irracional interiorizar toda información fáctica entregada por cualquier tercero, es decir, asumir toda pretensión de verdad. El mero hecho de enunciar algo no implica que ese algo sea aceptado como funcionalmente verdadero, esto es, como algo que puede generar un consenso útil; aceptarlo podría simplemente conducir al fracaso. Aunque el lenguaje y el habla, en su dimensión de habla constatativa, sirvan a la constitución de un mundo objetivo compartido, la forma en que ese consenso sobre el mundo se construye varía. Al respecto, Habermas distingue dos formas de rendimiento realizativo de las pretensiones de verdad entabladas en actos de habla constatativos.

45 Véase Habermas (2004) pp. 248-250. 
Por un lado, el habla permite un tipo entendimiento comunicativo en aquellas situaciones en que la pretensión de verdad puede ser aceptada ingenuamente sin más para permitir un entendimiento simple sobre el mundo. Esto sucede en todos los casos en que el acto de habla se refiere a una cuestión simple que no puede ser problematizada plausiblemente. A ello, Habermas le denomina acción comunicativa. Pero también puede suceder que la pretensión de verdad entablada mediante un acto de habla constatativo pueda ser problematizada de forma plausible. Esto se da en los casos complejos, esto es, en los casos en que es plausible dudar que la interpretación del mundo expuesta lingüísticamente como siendo realmente del caso sirva como descripción del mundo, lo que en principio tiene lugar de forma particularmente problemática en el ámbito de las ciencias naturales, pero no se limita a ello ${ }^{46}$. Cuando una pretensión de verdad se problematiza, ella debiera ser evaluada a través de discursos, es decir, argumentaciones en condiciones ideales (o cercanas a lo ideal), cuyo objeto es precisamente determinar a partir de una discusión sobre los argumentos de las partes cuál es el mejor consenso al que se puede llegar al respecto. La verdad sería el consenso que se alcanza en una situación ideal de habla referida a un discurso.

La reconstrucción de Habermas pretende cubrir tanto nuestras intuiciones relativas al concepto de verdad, como la forma en que tienen lugar las argumentaciones de las ciencias y la forma en que el concepto de verdad cumple su función tanto desde el punto de vista de la teoría del lenguaje como del de una teoría de la sociedad. Es decir, la teoría del discurso debe ser entendida como una forma de conciliar nuestra falibilidad cognitiva y la racionalidad de nuestras prácticas. Con ello, en parte, la teoría del discurso pretende superar los límites del pragmatismo tradicional e intenta construir un concepto fuerte de verdad. Verdad no debiera ser entendido simplemente como un equivalente en un ámbito específico de "utilidad" - no es verdadero lo que sea más útil que creamos-, sino lo que en condiciones ideales sea más racional que creamos. Pese a esta particularidad, el así llamado concepto consensual de verdad, en el fondo, no es más que una teoría pragmática sofisticada. Todas las argumentaciones necesariamente tienen lugar con limitaciones respecto de lo que pueda ser aceptado, como representación aceptable de la verdad, en el futuro. Ello implica que, aun bajo condiciones ideales, el consenso sobre lo que es verdadero puede no ser equivalente a lo verdadero, en el sentido de lo que sea realmente del caso (i.e. lo que realmente haya sucedido, lo que realmente tenga lugar o lo que realmente vaya a tener lugar, dependiendo de la orientación diacrónica del enunciado ${ }^{47}$. Precisamente por ello, asumiendo la existencia de un mundo que existe con independencia de nuestras creencias a su respecto, lo que establezca la argumentación no tiene por qué coincidir con lo que sea del caso. En parte, esto pretende ser solucionado con el postulado de la necesidad de una situación ideal de habla, es decir de un contexto de argumentación que, por ser puramente ideal en el sentido de una idea regulativa, no puede ser real. Eso ya pone en duda la relevancia que ello pueda tener para caracterizar al concepto mismo. Pero aun cumplidas las

\footnotetext{
46 Piénsese, por ejemplo, en el caso de la justificación de enunciados de hecho de los jueces. Tanto por la relevancia de las consecuencias de su establecimiento - determinante en el ejercicio de la coacción del Estadocomo por la imposibilidad de una verificación sensible directa, su aceptación suele no poder tener lugar bajo la forma de " acción comunicativa ". Al respecto, véase Infra.

47 Así el propio Habermas (2004) p. 258-260.
} 
condiciones formales del contexto ideal de habla, no solo es posible sino que es probable que el consenso alcanzado sobre la verdad deba cambiar con posterioridad asumiendo los mismos presupuestos pragmáticos. El modelo del consenso y de la situación ideal de habla descansa sobre la base de una equiparación entre el concepto de conocimiento falible racionalmente justificado, en tanto forma de dar cuenta del carácter racional de las ciencias y otras prácticas orientadas al establecimiento de enunciados justificados, y el concepto de verdad, en tanto pretensión a la que tienden esos discursos. El concepto discursivo de verdad es, por ello, un concepto orientado a dar cuenta de las razones por las cuales podemos comportarnos como conociendo la verdad al cumplirse condiciones definidas por las prácticas en cuestión, sin que ello signifique que esa asunción no pueda demostrarse errada en el futuro ${ }^{48}$. Esto, por cierto, es difícilmente conciliable con el objeto del concepto de verdad, el cual precisamente no tematiza las condiciones bajo las cuales uno puede darse por satisfecho, sino el objeto de ese darse por satisfecho.

Esto es precisamente lo que ha llevado a Habermas a reformular su teoría para pasar a tratar al concepto de verdad como algo "no epistémico" ${ }^{49}$. Si bien, en la propia comprensión de Habermas, la teoría del discurso es la mejor forma de dar cuenta de la forma en que nuestras prácticas de comprensión del mundo complejo funcionan en un contexto falible, la equiparación de un concepto racional de justificación del conocimiento con lo que se entiende por verdad escondería las particularidades del concepto de verdad. Mientras en su formulación primera de la teoría de la verdad, Habermas consideraba que la justificación ideal de un enunciado descriptivo tiene que ser tenida por sinónimo de verdad, dando cuenta con ello de la racionalidad de las prácticas de justificación de enunciados descriptivos propias de las tradiciones científicas, en "Verdad y justificación” Habermas ha tendido a asumir la necesidad de separar ambas cuestiones, haciendo referencia a lo que denominó un concepto no epistémico de verdad, esto es, a un concepto de verdad que no se encuentra ligado a lo que podemos conocer ni a las formas en que podemos intentar justificar conocimiento. Así, el concepto de justificación consumía en su primera formulación completamente al segundo (equiparar verdad y justificación implica en realidad eliminar el concepto de verdad), mientras que en su formulación más reciente, Habermas pasó a dar cuenta de la imposibilidad de conciliar ambos conceptos: la racionalidad pragmática en la justificación de conocimientos simplemente no es equivalente a lo que sea objetivamente verdadero ${ }^{50}$. Ello, por cierto, no implica alterar en nada la idea central relativa a que para efectos de nuestra conducción en el mundo de la acción, aquello que se encuentre justificado y resista cualquier intento de crítica racional tiene que ser tenido por verdadero en un sentido puramente pragmático (es decir, en cuanto parámetro de orientación de la conducción de nuestras acciones). A ello corresponde el concepto de justificación. Que ello describa correctamente aquello que realmente tiene lugar en el mundo o no, es algo que por definición no

\footnotetext{
48 Concediendo el punto, véase Habermas (2004) p. 260.

49 Véase Habermas (2004) pp. 246 ss.

50 Véase, sobre todo, Habermas (2004) pp. 246-250.
} 
puede comprobarse dado todo lo demostrado tanto por la teoría del conocimiento como por la teoría del lenguaje $\mathrm{e}^{51}$.

Como pretendo demostrar, bajo incorporación de un concepto no epistémico de verdad y de un concepto epistémico de justificación dada por prácticas institucionales -en este caso, la valoración de la prueba por parte de la administración de justicia-, desaparecen todas las aporías que parecen afectar a los delitos de falsedad por su dependencia de conceptos aparentemente metafísicos. Esa desaparición de perplejidad implica, a su vez, ruptura parcial de la dogmática de los delitos de falsedad con las teorías filosóficas de la verdad. "Del conflicto filosófico fundamental respecto al concepto de verdad no puede esperarse ninguna solución para el conflicto entre teorías objetivas y subjetivas de la verdad [en el falso testimonio]"52. Esto, por cierto, puede parecer a primer vista desilusionador. Pero esa desilusión es, en realidad, signo de normalidad. En ese sentido, el tratamiento filosófico de la verdad y su incorporación en la dogmática de los delitos de falsedad tiene un carácter esclarecedor que resulta contraintuitivo con su propio carácter conflictivo: el tratamiento a partir de las teorías de la verdad permite dar cuenta no solo de la estructura de los delitos de falsedad (d), sino también de la normalidad institucional de los delitos de falsedad en sentido estricto (c).

\subsection{Normalidad institucional de los Delitos DE FAlSEDAD}

Central para estos efectos es el esclarecimiento de la normalidad institucional de los delitos de falsedad revelada contraintuitivamente por tematización de las teorías de la verdad. Contra lo que puede parecer, los delitos de falsedad no incorporan una concepción de la relación entre hechos y sentencia que sea distinguible de cualquier otra sentencia; no hay en ellos ninguna recepción de la teoría de la correspondencia que sea demostrada imposible por las críticas a esta. Toda sentencia judicial implica la asunción de una pretensión de correspondencia de los enunciados de hechos que sirven de premisa a la resolución del caso con la realidad de lo sucedido y tematizada mediante esa reconstrucción de los hechos. Es una necesidad ya lógica de nuestras prácticas jurídicas, el que el juez dé por conocida la realidad de los hechos al dictar sentencia. Por supuesto, puede ser que el juez la dé precisamente por incierta: el rechazo de una pretensión civil o la declaración de inocencia pueden basarse simplemente en ausencia de prueba por parte de quien tenía la

\footnotetext{
51 Por cierto, Habermas no responde directamente a la pregunta respecto a la forma de etiquetar no ya el concepto de "justificación" sino el concepto de "verdad" desde el punto de vista de las clasificaciones tradicionales de teorías de la verdad. Una cosa es segura al respecto: la distinción entre verdad y justificación implica una fisión entre el carácter pragmático y no pragmático de la teoría del discurso. Al no hacer referencia el concepto de verdad ya a las condiciones de justificación de un enunciado desde el punto de vista de la racionalidad de la acción -todo ello consumido por el concepto de justificación- su concepto "no epistémico" de verdad no puede considerarse tampoco un concepto pragmático de verdad. Uno podría pensar, por ello, que se trata de una vuelta a la teoría de la correspondencia: Habermas pasaría a aceptar que un enunciado sería verdadero en caso de corresponder a la realidad. Pero aunque eso no sea incorrecto, el concepto no epistémico de verdad es precisamente una ruptura con uno de los presupuestos centrales de la teoría de la correspondencia: el reconocimiento de un vínculo conceptual entre verdad y conocimiento. Mientras la teoría de la correspondencia se asume como una teoría de justificación de conocimiento, el concepto no epistémico de Habermas asume un rechazo de esa idea. Como teoría del conocimiento, Habermas sigue defendiendo fuertemente la teoría del discurso.

52 Hilgendorf (1993) p. 558. Así también véase Mưller (2000) p. 85. En contra Kaufmann (1992) pp. 127 y ss.
} 
carga probatoria. Pero ello no hace más que dar cuenta de situaciones deficitarias; en las situaciones no deficitarias, el juez tiene que dar por conocidos los hechos para poder aplicar el derecho.

El conocimiento producido por medio de valoración de la prueba, tiene lugar en condiciones particularmente débiles. Las aporías que parecen subyacer a los delitos de falsedad no son más que un reflejo de ese problema central del derecho. Frente a ello, el derecho solo puede responder mediante el reenvío a nuestras condiciones deficitarias de conocimiento de hechos pasados: la práctica jurisdiccional fija, en distintos contextos, estándares de conocimiento bajo los cuales enunciados de hecho aparecen como justificados pese a no existir garantía de correspondencia. La determinación de las razones de las fijación de los estándares de conocimiento no pueden, por ello, explicarse con una simple referencia a la teoría de la correspondencia. Al igual que en el caso de las ciencias, el derecho asume la falibilidad que las teorías de la verdad con pretensiones trascendentes no pueden asumir.

Bajo qué condiciones es racional aceptar esa falibilidad, es algo que solo puede ser respondido a través de presupuestos pragmáticos y con ello la respuesta se puede plantear de mejor forma si se acepta que, siguiendo la distinción de Habermas, en realidad no hay determinación de verdad judicial sino de justificación, esto es, de establecimiento de hechos como ciertos bajo presupuestos racionales al tipo de acción al que sirven como presupuesto. Esto puede entenderse con un paralelo frente a las ciencias. Las ciencias operan ciertamente con aceptación de su saber falible, pero con control de la determinación de lo que aceptan como conocimiento racionalmente justificado de forma consecuente con la propia comprensión de su función. De acuerdo a la teoría del discurso, las teorías científicas aceptan como condición de justificación (o de verdad en sentido débil) el que a partir de la asunción de la corrección de un principio de inducción, los enunciados de la teoría que logre imponerse al resto sean tenidos por verdaderos en la orientación a la acción hasta que no se demuestre falso. Esas son condiciones argumentativas de conciliación de las distintas necesidades que comprende el concepto de justificación y que permiten conciliar la orientación a la acción y la orientación incondicionada al conocimiento.

La relación entre hechos imputados y derecho tiene que asumirse, en parte, con una lógica similar (en ambos casos se trata de conciliación de necesidades de acción y limitaciones en el establecimiento de sus presupuestos), y en parte con una lógica completamente distinta (ya que el tipo de necesidad de acción que le corresponde es distinta). Al igual que los discursos científicos, el proceso es una forma de conciliación de la necesidad de acción del derecho con las limitaciones en la posibilidad de conocimiento de hechos pasados. El tratamiento de esas condiciones de limitación discurre por dos extremos: la cosa juzgada y la teoría de la prueba.

Por una parte, a diferencia de las ciencias, el derecho asume que sus acciones -en particular la sentencia judicial- sirven al otorgamiento de necesidades de certeza y que, por ello, no puede estar abierto, en general, a revisión. Desde el punto de vista de la justificación de los hechos en el proceso, la cosa juzgada expresa precisamente lo anterior: salvo en las condiciones limitadas por la acción de revisión, la posibilidad de demostración de error en la justificación de enunciados fácticos es irrelevante. 
Por otra parte, la determinación de las condiciones de producción de la prueba y de las condiciones de justificación de enunciados por referencia a la prueba ("valoración de la prueba”) se construye como una respuesta pragmática a las necesidades de acción propias de cada rama del ordenamiento jurídico. Así, en el derecho privado la idea que la acción a la que el establecimiento de los hechos sirve de presupuesto tiene por objeto resolver conflictos privados da lugar a la aplicación de un principio dispositivo bajo el cual tiene que ser tenido por cierto aquello que las partes den por cierto, mientras en materia penal, las condiciones de justificación de estos asumen presupuestos mucho más estrictos y una limitación mayor de la posibilidad de error.

La determinación específica de los límites de estas dos cuestiones centrales en el concepto de justificación propio del derecho y del proceso es ajena a este trabajo. Lo único relevante es resaltar solo un punto: el así denominado concepto de "verdad" del derecho, asumiendo el carácter fuerte de este, no es en realidad un concepto de verdad sino de "justificación”, respecto del cual la determinación de las condiciones de producción de esta justificación se basa en la especificación de las condiciones bajo las cuales un enunciado sirve como presupuesto racional a una acción coercitiva justificada.

Nada de esto cambia en el caso de los delitos de falsedad en sentido estricto. Aquí, el discurso del proceso no hace nada que sea analíticamente distinguible de la forma normal de operación del derecho. En los delitos de falsedad se imputa discordancia entre lo que era del caso (determinado por los enunciados justificados del juez) y lo que fue declarado por el imputado, de la misma forma en que en un caso cualquiera de derecho penal el juez tiene que determinar si existe una relación de concordancia entre los enunciados descriptivos que sirven de presupuesto a la acusación y los enunciados de hechos que sean justificables a ese respecto. En otras palabras, en la imputación de falta de correspondencia entre enunciados efectuados por el imputado y enunciados justificados por el juez no hay ninguna diferencia lógica con la imputación de correspondencia entre acusación y realidad constituida por los enunciados justificados del juez. Que aquí existan dos niveles de pretensión de correspondencia -(i) correspondencia entre acusación/imputación (el autor habría dicho $\mathrm{x}$ y x era falso) y realidad (el autor dijo x y x era falso); y falta de correspondencia entre declaración/documento $(\mathrm{x})$ y realidad $(\mathrm{y})$ - no implica nada que no sea efectuado por toda otra sentencia que dé por establecidos hechos.

\subsection{TeOrÍAS DE LA VERDAD Y EL CONCEPTO DE FALSEDAD: LAS LlaMADAS TEORÍAS DE}

LA FALSEDAD

El segundo rendimiento dogmático de la tematización del concepto de falsedad a partir de comparación con el concepto general de verdad dice relación con el esclarecimiento de la estructura del tipo objetivo de aquellos delitos que contienen directamente al concepto de "falsedad". Dogmáticamente el tipo de teorías que tematizan de mejor forma este esclarecimiento de estructuras son las así llamadas teorías de la declaración falsa (también llamadas teorías de la declaración o teorías de la falsedad) ${ }^{53}$. La determinación del

\footnotetext{
53 Sobre las distintas posturas, véase solo PAUlus (1987) pp. 437 ss., con innumerables referencias ulteriores; Müller (2012) $\$ 153$ Nm. 41 y ss.; y Vormbaum (2013) $\$ 153$ Nm. 60 y ss. En español puede consultarse el texto traducido de STEIN (2008) pp. 11 y ss.
} 
contenido de injusto descrito mediante el concepto de declaración falsa (falsche Aussage) del $\$ 153$ StGB -equivalente a "faltar a la verdad" en nuestro artículo 206 CP- constituye un tópico relevante de discusión de la dogmática de la Parte Especial en Alemania. De acuerdo a una sentencia de Paulus, se trataría de una "prominente, y aparentemente sin salida, disputa centenar" ${ }^{54}$. Sin dudas, la enorme cantidad de atención recibida por un tipo de interés general mucho menor a otras grandes discusiones de la Parte Especial (por ejemplo, la determinación de los supuestos de homicidio calificado o la definición de la custodia en los delitos contra la propiedad) puede ser explicada por la posibilidad de vincular directamente la discusión con la glamorosa disputa filosófica de las teorías de la verdad. Esto es: en parte, la disputa dogmática relativa al concepto de "falsedad" en el falso testimonio ha tenido lugar de forma paralela a la discusión relativa al concepto filosófico de verdad ${ }^{55}$. Sin embargo, como se ha mostrado, la pretensión de definir directamente la falsedad a partir de una disputa sobre teoría del conocimiento constituye un error.

Lo anterior no quiere decir que las teorías de la falsedad constituyan un error dogmático. Contra lo que parece, la disputa sobre el contenido de injusto del falso testimonio no es realmente una disputa sobre la teoría de la verdad aplicable. En su mejor versión, las teorías de la falsedad constituyen especificaciones analíticas sobre los objetos de comparación en la determinación de la relación que constituye a la falsedad, esto es, el tratamiento del concepto de verdad y de falsedad en la determinación del contenido de injusto del falso testimonio debe tener por objeto despejar dificultades estructurales ilusorias o reales ${ }^{56}$ y no se trata, en cambio, de pretender determinar el contenido de injusto directamente por referencia a una disputa epistemológica o metafísica ${ }^{57}$. Ya que los delitos de falsedad siempre funcionan estructuralmente sobre la base de una comparación, las teorías de la declaración falsa especifican los objetos que se comparan al verificar la realización del tipo objetivo del falso testimonio.

En parte, la disputa siempre se ha visto oscurecida por la fijación casi exclusiva en el segundo par de la relación. Casi cualquier descripción de la acción punible del falso testimonio tiene que partir de la base de que se compara "lo declarado" con el objeto que determina su falsedad. En lo esencial, las teorías de la declaración falsa se concentran en especificar el objeto que determina la falsedad. Es decir, se trata de la determinación de si la declaración debe ser discordante con lo subjetivo del testigo (percepción original y recuerdo actual son los grandes candidatos de las llamadas teorías subjetivas, pero ambos pueden ser agrupados bajo el concepto impreciso de conocimiento ${ }^{58}$ ) o con la realidad de los he-

\footnotetext{
54 Paulus (1987) p. 436.

55 La dependencia central de la disputa dogmática respecto del conflicto filosófico es sobre todo sostenida por Kaufmann (1992) pp. 125 ss. y, en menor medida, véase Kargl (2003) pp. 794 ss.

56 Hilgendorf (1993) pp. 547-548.

57 Similar en la descripción del contenido de la disputa KüPER (2005) p. 31; Müller (2000) pp. 82 y ss.; Vormbaum (1987) pp. 253 y ss.; Vormbaum (2013) \$153 Nm. 57 y ss.; Hilgendorf (1993) pp. 558-559; Hruschka-Kässer (1972) p. 710; Paulus (1987) pp. 436-437; Lenckner/Bosch (2010) Vorbem. \$\$ $153 \mathrm{ff.}$ Nm. 4; Wolf (1991) pp. 177-178.

58 Esta es la reducción conceptual tradicional para contraponer las teorías subjetivas a las teorías objetivas (reducidas a partir del concepto de realidad). Así, por ejemplo, véase Gallas (1957) p. 315; KaUfmann (1992)
} 
chos respecto a los cuales este declara. Recientemente Kargl ha insistido con razón en que parte importante de los conflictos que pueden encontrarse en la interpretación del concepto de falsedad pueden ser evitados, si uno determina antes que cuenta como "declaración" (o peritaje o traducción, dependiendo del rol procesal) y así define por ambos lados la relación que fija la punibilidad del falso testimonio ${ }^{59}$. No es necesario insistir aquí sobre el sentido exacto que debe dársele al concepto de declaración: eso es una pregunta específica de la dogmática del falso testimonio, no de una introducción general a los delitos de falsedad. Lo crucial en la dogmática general de los delitos de falsedad es que ese primer elemento que determine la relación propia de un delito de falsedad necesariamente tiene un componente funcional en su determinación: esto es una premisa dogmática que es sin más extensible a los demás delitos de falsedad en sentido estricto, cuya estructura de determinación del tipo objetivo también es relacional ${ }^{60}$.

Esta fijación teleológica del primer elemento de la relación se deja especificar en el caso del testimonio. Debido que en el falso testimonio se trata de la protección del proceso como contexto de fiabilidad cognitiva para la administración de justicia ${ }^{61}$, declaración solo puede ser aquello que es susceptible de tener valor probatorio en el conjunto de expresiones enunciadas por un testigo ${ }^{62}$; todo lo demás no afecta ni siquiera en abstracto a la administración de justicia. Una definición de ese tipo puede ser formalmente asimilable en otros delitos de falsedad -en particular, si uno sigue la teoría del valor probatorio del documento como determinante en el contenido de injusto de las falsedades documentales-, pero en ningún caso puede ser sustancialmente equivalente.

La determinación precisa del primer par de la relación -el portador de verdad/autenticidad o falsedad- solo limita las posibilidades de caer en confusiones evitables en la dogmática de los delitos de falsedad. En cualquier caso, el centro de interés de las teorías de la declaración falsa y de la dogmática de los delitos de falsedad se encuentra en la determinación de las condiciones bajo las cuales el objeto en cuestión es falso, es decir, en el segundo elemento

pp. 119-120; Kargl (2003) p. 794; KindhäUser (2012) \$ 46 Nm. 14 y 17; KüPer (2005) pp. 31-32; Paulus (1987) p. 438; Отto (1984) p. 163; LencKner/Bosch (2010) Vorbem. \$\$ 153 ff. Nm. 4; Müller (2012) \$ 153 Nm. 42 y 47; cfr. Vormbaum (2013) \$153 Nm. 60.; Wolf (1991) p. 178.

59 Kargl (2003) pp. 793-795. Así ya antes Wolf (1991) p. 179.

${ }^{60}$ Respecto a la estructura relacional de la falsedad documental, véase solo FreUnd (2010) Nm. 136 y ss. y Cramer/Heine $(2010) \$ 267$ Nm. 48 ss. Sobre la estructura relacional de todo delito de falsedad, Binding (1997) pp. 115 y ss. En principio, la relación tiende a ser más simple que en el caso de la declaración: basta de la adjudicación interpretativa a un documento del sentido comunicativo de ser de autoría de alguien en condiciones que es de autoría de otro, para que el tipo objetivo se encuentre realizado. En el caso de las formas tipificadas de falsedad ideológica -mentiras escritas- (\$271 y 348 StGB principalmente en Alemania), la cuestión vuelve a adquirir complejidad, con lo que el recurso limitado al concepto de verdad se hace inevitable. Véase Cramer/Heine (2010) \$271 Nm. 21-26; y Kindhäuser (2012) \$58 Nm. 1.

${ }^{61}$ Al respecto véase, Wilenmann (2011) pp. 570-572. Véase también Vormbaum (2013) Vor $\$ \$ 153$ ff. Nm. 2 y ss.

${ }^{62}$ Es demasiado apresurado deducir de esto que solo constituye "declaración" la enunciación de afirmaciones directas sobre los hechos objeto de prueba. También las afirmaciones relativas a circunstancias de conocimiento pueden influir en la concesión de valor probatorio, por lo que no existen razones teleológicas inmediatas para excluirlas del concepto de declaración. 
en la relación que da lugar a falsedad ${ }^{63}$. En el caso del falso testimonio, las teorías de la falsedad tienen básicamente tres posibilidades bajo dos modalidades a su disposición: el objeto de comparación es la realidad de los hechos sobre los que se declara (teorías objetivas), el recuerdo actual ${ }^{64}$ de los hechos (teorías subjetivas, cuya especificación puede ser designada como "subjetivas de fijación presente" ${ }^{75}$ ), la percepción original de los hechos (teorías subjetivas de fijación pasada), siendo el objeto respectivo invariablemente el mismo (teorías estrictas) o dependiendo del rol procesal (teorías de la obligación y otras teorías modificadas) o de la forma de la declaración (teorías contextuales) ${ }^{66}$. Aunque semánticamente las teorías de la declaración falsa se presentan dependientes de tres variables que funcionan en un mismo nivel, se trata en realidad de una combinatoria de tres elementos con dos permutas: los tres objetos de comparación respectivos se ven especificados bajo las variables estricta/modificada y contextual/ no contextual ${ }^{67}$. Por ello, es posible sostener con sentido una teoría objetiva estricta contextual (por defecto, la declaración se compara con la realidad, a menos que el testigo declare estar dando cuenta solo de su recuerdo o de su percepción) o una teoría subjetiva de fijación presente, modificada y contextual (aquello que se compara depende del rol procesal y de la forma de la declaración; en caso que la declaración sea derechamente afirmativa, el objeto de comparación es el recuerdo). Así, el número de teorías de la declaración falsa que pueden, en principio, ser sostenidas con sentido es 12 .

En lo que aquí interesa (es decir, lo que no es propio de la dogmática del falso testimonio), la cuestión crucial es la determinación del contenido (y no de la modalidad) de la falsedad: objetiva o subjetiva. Contra lo que aparece, esta cuestión no se ve afectada en nada por las polémicas filosóficas respecto al concepto de verdad ${ }^{68}$. De lo que se trata es de fijar el punto de referencia en el enunciado del juez que sirve de comparación con la declaración del testigo para establecer correspondencia o falta de ella. Quien sostiene una teoría

\footnotetext{
63 Así también Vormbaum (2013) \153 Nm. 56; Küper (2005) p. 31; Wolf (1991) p. 177.

${ }^{64}$ HruschKa y KäsSER (1972) p. 710, identifican una variable y, por lo mismo, un elemento adicional en una teoría del recuerdo potencial: no se trata de lo que recuerde el testigo en los hechos, sino de lo que puede exigirse que recuerde. La imposibilidad de acceder a estados mentales puros de otro hace que la distinción sea, sin embargo, irrelevante. Precisamente por ello, Hruschka y Kässer denominan a las teorías sin fijación potencial (normativa) como "subjetivas extremas" y las descartan. Toda teoría subjetiva con fijación presente tiene que ser, en realidad, potencial.

65 Paulus (1987) p. 438 las denomina teorías subjetivas estrictas. Esa nomenclatura induce, sin embargo, a confusiones, ya que la calificación estricta/modificada tiende a ser utilizada, a su vez, para determinar la variabilidad del objeto dependiendo del sujeto de la declaración.

${ }^{66}$ Con mayor detalle véase Kargl (2003) pp. 796 y ss.; Müller (2000) pp. 54 y ss; Vormbaum (1987) pp. 253 y ss; PAUlus (1987) pp. 437 y ss.; ОтTо (1984) pp. 161-162. La nomenclatura solo es coincidente en contraponer objetivo a subjetivo. El etiquetamiento posterior de las teorías -en particular, de la teoría de la obligación y en general de toda modificación de las posturas iniciales- es extremadamente plurívoco y, en muchos casos, confuso. Por eso, he preferido reconstruirlo antes como combinación analítica que, suele ser el caso, como presentación semántica directa.

67 Es posible, además, reconocer variantes ulteriores de las teorías objetivas, las que son en algunos casos subjetivizadas de modo de hacer al objeto de comparación no dependiente de la "realidad", sino de aquello que habría sido perceptible por un tercero cualquiera (o por alguien con ciertas características) en la situación del testigo. Al respecto véase solo PAulus (1987) p. 438. Ello hace que la combinatoria sea algo más compleja que tres elementos con dos permutas. La cuestión no tiene, sin embargo, ninguna relevancia aquí.

68 Así, sin embargo, KaUfmann (1992) pp. 119 ss.
} 
objetiva sostiene al mismo tiempo que la sentencia condenatoria debe dar probado que el enunciado que constituye a la declaración no coincide con una reconstrucción alternativa de lo mismo por parte del juez; esa reconstrucción alternativa es, por ello, parte de lo que debe argumentarse que se encuentra probada para que el tipo objetivo puede ser dado por realizado. Como por hipótesis la reconstrucción del juez se encuentra justificada en ese sentido particular, es "verdadera"-, el contenido de la declaración admite ser reconstruido como injustificado y, por ello, falso. No se trata por ello, contra lo que aparece, de una toma de posición por la teoría de la correspondencia como teoría de la verdad ${ }^{69}$.

Desde el punto de vista del objeto funcional del testimonio, las teorías objetivas manifiestan una cierta preeminencia. El objeto del testimonio -la obligación del testigo- no es dar cuenta de recuerdos personales, sino de hechos que deben ser probados para permitir la dictación de la sentencia con base cognitiva adecuada. Las teorías subjetivas son, en general, reactivas a las teorías objetivas: ellas parten de la base que las teorías objetivas exigen al testigo más de lo que puede estar en condiciones de rendir, en particular cuando existen problemas de memoria o de percepción, por lo que les afectan problemas de legitimación ${ }^{70}$. Así, toda declaración solo podría exigirse de un testigo que reproduzca representaciones internas de este, ya que los objetos solo serían conocibles a través de representaciones de ellos y nunca directamente ${ }^{71}$. La crítica apunta, pese a su extraña fijación en la teoría del conocimiento, a dar cuenta de los eventuales problemas sinceros de rendimiento de la memoria o de la percepción que pueden darse en un testigo ${ }^{72}$. La pregunta es, sin embargo, si el rendimiento de la memoria o de la percepción forma parte del tipo objetivo o del tipo subjetivo. Quien sostiene una teoría subjetiva de fijación presente -la que en mayor medida pretende dar cuenta de la posición del testigo- pretende con ello evitar tener que tratar los problemas de rendimiento de la memoria como simples componentes en la determinación del dolo y de la imprudencia. De esta forma, la declaración falsa por problemas reales de memoria no sería ni siquiera objetivamente típica, ya que no implicaría ninguna infracción

\footnotetext{
69 Similar Kargl que ciertamente verifica una coincidencia superficial entre la teoría de la correspondencia y las (por él también defendidas) teorías objetivas de la declaración falsa. Como él mismo aclara, verdad solo puede tener la posición de idea regulativa (de "principio") en la práctica jurídica, con lo que no puede haber aplicación de una teoría fuerte de la correspondencia. Véase KARGL (2003) pp. 798-799 y 800 y ss.

70 Existe una crítica adicional que es relevante en relación con las teorías objetivas pero que afecta solo al falso testimonio y no forma parte, por lo tanto, de la dogmática general de la falsedad. El argumento es el siguiente: no solo la declaración discordante con la realidad es peligrosa para la administración de justicia, también la declaración que casualmente resulta coincidente con la realidad es relevante, por lo que no puede tratarse solo de tentativa inidónea. Al respecto, con mayor detalle PAulus (1987) pp. 440 ss. El argumento parte de una base correcta, pero asume que las teorías objetivas no pueden controlar esto por tomar un concepto demasiado restringido de declaración. Si la declaración incluye, a su vez, las circunstancias relevantes para otorgar valor probatorio, la declaración mentirosa respecto a la percepción de algo que no fue permitido es falsa con independencia de que lo declarado resulte ser verdadero.

71 Locus classicus de esta especie de utilización dogmática de la distinción entre cosa en sí y fenómeno es el tratamiento de Binding (1997), p. 134. Así también Gallas (1957) p. 315. Véase también Отто (1984) y 162; con ulteriores referencias. Crítico respecto a la capacidad de rendimiento de este argumento BADURA (1957) pp. 401-403.

72 Con mayor detalle, véase Müller (2000) pp. 83-85.
} 
de obligación ${ }^{73}$. Esa fijación inicial es correcta: el castigo por decir algo falso sin saber que es falso parece difícilmente justificable. Pero las teorías subjetivas parten de la base que la realización del tipo objetivo no imputable implica algún grado de reproche y/o la imputación de la infracción de una obligación. Precisamente por ello es que la crítica se presenta como una crítica de legitimidad: ese reproche o esa afirmación de infracción de obligación del testigo no podría encontrarse justificado, porque al no recordar o no conocer la verdad, no podía cumplir la supuesta obligación ${ }^{74}$.

El problema de la crítica no se encuentra, por ello, solo en su tratamiento del problema de Parte Especial correspondiente, sino en una asunción incorrecta de Parte General, a saber, que aquello que no resulta imputable es necesariamente expresivo de un reproche mínimo o, al menos, de relevancia normativa como infracción de alguna obligación. El falso testimonio demuestra precisamente que esa asunción es errada ${ }^{75}$. El objeto del dolo es justamente dar cuenta del cumplimiento de las condiciones situativas bajo las cuales la conducta objetivamente antinormativa se deja reconstruir como verdadera infracción de la norma de comportamiento ${ }^{76}$; sin dolo (o, en caso de ser aplicable, imprudencia), no solo no hay reproche alguno posible, sino que ni siquiera puede afirmarse la existencia de un injusto objetivo que dé lugar, por ejemplo, a reacciones no dependientes de la infracción de una obligación.

Ello quiere decir que las teorías objetivas -si modificada/estricta y contextual/no contextual forma parte de una discusión distinta que solo integra la dogmática del falso testimonio- se dejan manejar correctamente con un concepto adecuado de dolo. Así, la falsedad admite reconstruirse correctamente bajo su forma intuitiva, es decir, como no correspondencia entre declaración y realidad, la que se ve fijada por el enunciado justificado (por prueba) del juez.

\section{CONCLUSIONES}

Las principales conclusiones de esta introducción a la dogmática de los delitos de falsedad pueden ser rápidamente presentadas:

- Los delitos de falsedad constituyen una subcategoría de delitos de expresión caracterizada por una estructura relacional. En todo delito de falsedad -sea falsedad proposicional, falsificación o imputación falsa-, se imputa falta de discordancia entre objeto de la imputación y objeto de la referencia, con lo que la expresión admite ser reconstruida como infracción de una pretensión de verdad.

\footnotetext{
73 Así Gallas (1957) pp. 317-319

74 Similar Lenckner/Bosch (2010) Vorbem. \$\$ 153 ff. Nm. 6.

75 Así también HruschKa/Kässer (1972) p. 710.

76 Al respecto, WilenMANn (2013) sección 4. En lo referente al falso testimonio, precisamente por ello HruschKa/Kässer (1972) p. 710; y LencKner/Bosch (2010) Vorbem. \$\$ 153 ff. Nm. 6; critican la confusión de los conceptos de "falsedad" -componente del tipo objetivo- e infracción de deber que subyace a toda teoría subjetiva. Similar KindHäUSER (2012) §46 Nm.20.
} 
- El concepto de falsedad designa siempre una relación de este tipo. En el caso de los delitos de falsedad proposicional, la discordancia se constituye entre declaración (enunciado lingüístico constitutivo de un acto de habla constatativo) y realidad; esto puede ser designado falsedad en sentido estricto.

- Pese a su apariencia, la falsedad en sentido estricto no implica una recepción de la teoría de la verdad como correspondencia. La práctica jurídica literalmente no puede recibir o rechazar teorías del conocimiento. El concepto de falsedad en sentido estricto y la disputa a su respecto -ilustrada en su mejor forma por las llamadas teorías de la declaración falsa- solo constituye una especificación de la estructura relacional propia de todo delito de falsedad.

- Al igual que en el caso de las teorías de la declaración falsa, la tematización dogmática del tipo objetivo de los delitos de falsedad admite, en general, ser reconstruida como una pretensión de esclarecimiento de la estructura relacional del contenido de injusto del tipo en cuestión. En algunos casos, esa relación es evidente: que la falsificación del oro, por ejemplo, admite ser reconstruida como la producción de un objeto con pretensiones de pasar por oro y su falta de correspondencia con el objeto real (oro), es algo que no puede sorprender a nadie. Esa estructura relacional se torna más complicada, sin embargo, en los casos de las distintas formas de falsedad documental. Dada su relevancia práctica, la producción de un análisis de las estructuras de las formas de realización de los distintos tipos de falsedades documental es una tarea sumamente relevante pendiente. El presente artículo solo pretende clarificar la tarea.

\section{BIBLIOGRAFÍA CITADA}

Badura, Peter (1957): "Erkenntniskritik und Positivismus in der Auslegung des Meineidstatbestandes", en Goltdammer's Archiv für Strafrecht 1957, pp. 397-404.

Berner, Albert Friedrich (1986): Lehrbuch des deutschen Strafrechts (Aalen, Scientia Verlag; reimpresión del original de 1898, Leipzig, Bernhard Tauchnitz, decimoctava edición).

Binding, Karl (1997): Lehrbuch des gemeinen deutschen Strafrechts. Besonderer Teil, Band 2 (Goldbach, Keip Verlag; reimpresión del original de 1904, Leipzig, Engelmann, segunda edición).

Cramer, Peter, y Heine, Günter (2010): Comentario "Vorbem. \$\$ 267 ff."; “267 StGB” y “271 StGB”, en EsER et al. (edits.), Schönke/Schröder Strafgesetzbuch Kommentar (Múnich, Beck, vigesimoctava edición).

Etcheberry, Alfredo (1998): Derecho Penal, tomo IV (Santiago, Editorial Jurídica, tercera edición).

Freund, Georg (2010): Urkundenstraftaten (Berlín, Heidelberg, Springer, segunda edición).

Gallas, Willhelm (1957): “Zum Begriff der 'Falschheit' der eidlichen und uneidlichen Aussage”, en Goltdammer's Archiv für Strafrecht 1957, pp. 315-325.

Garrido Montt, Mario (2000): Derecho Penal Parte Especial, tomo IV (Santiago, Editorial Jurídica). 
Habermas, Jürgen (1989): Teoría de la acción comunicativa: complementos y estudios previos (Madrid, Cátedra).

Habermas, Jürgen (2004): Wahrheit und Rechtfertigung. Erweiterte Ausgabe (Fráncfort del Meno, Suhrkamp).

Hilgendorf, Eric (1993): "Der Wahrheitsbegriff im Strafrecht am Beispiel der strafrechtlichen Aussagetheorien ( $\$ \$ 153$ ff. StGB)", en Goltdammer's Archiv für Strafrecht 1993, pp. 547-559.

HruschKa, Joachim, y Kässer, Wolfgang (1972): "Der praktische Fall. Strafrecht: Die Eidesbrüder”, en Juristische Schulung 1972, pp. 709-715.

JaKOBS, Günther (2000): Urkundenfälschung (Colonia-Berlín-Bonn-Múnich, Carl Heymanns).

Kaufmann, Arthur (1992): "Die strafrechtlichen Aussagentheorien auf dem Prüfstand der philosophischen Wahrheitstheorien”, en ARZT et al. (edits.), Festschrift für Jürgen Baumann (Bielefeld, Verlag Ernst und Werner Gieseking), pp. 119-130.

KaNT, Immanuel (1974): "Kritik der reinen Vernunft I", en Werke in zwölf Bände (Werkausgabe), Weischedel, Willhelm (edits.), (Fráncfort del Meno, Suhrkamp).

Kant, Immanuel (1800): Logik, ein Handbuch zu Vorlesungen, Gоттloв Benjamin Jäsche (edit.), (Königsberg, Friedrich Nicolovius).

KARGL, Walter (2003): "Wahrheit und Wirklichkeit im Begriff der 'falschen Aussage' (\$\$ 153 ff. StGB)”, en Goltdammer's Archiv für Strafrecht 2003, pp. 791-806.

KERn, Eduard (1967): Los delitos de expresión (Buenos Aires, Depalma).

Kindhäuser, Urs (2012): Strafrecht Besonderer Teil I (Baden-Baden, Nomos, quinta edición).

KÜPER, Wilfried (2005): Strafrecht Besonderer Teil (Heidelberg, Müller).

LenCKNeR, Theodor y Bosch, Nikolaus (2010): Comentario "Vorbem. $\$ \$ 153$ ff.", en ESER et al. (edits.), Schönke/Schröder Strafgesetzbuch Kommentar (Múnich, Beck, vigesimoctava edición).

Mañalich, Juan Pablo (2005): ¿La comisión de delitos mediante la imputación de delitos?, en Revista Peruana de Doctrina y Jurisprudencia Penales 6, pp. 193-242.

Maurach, Reinhart; Schröder, Friedrich-Christian; Maiwald, Manfred (2005): Strafrecht Besonderer Teil Teilband 2 (Heidelberg, Müller, novena edición).

Merkel, Adolf (1867): Kriminalistische Abhandlungen. II. Die Lehre vom strafbaren Betruge (Leipzig, Breitkopf und Härtel).

Müller, Henning Ernst (2000): Falsche Zeugenaussage und Beteiligungslehre (Tubinga, Mohr Siebeck).

Müller, Henning Ernst (2012): Comentario “Vor $\$ \$ 153$ ff.” y “153 StGB” en JoecKS y Miebach (edits.), Münchener Kommentar zum Strafgesetzbuch, tomo 3 (Múnich, Beck).

Отто, Harro (1984): “Die Aussagedelikte, $\$ \$ 153-162$ StGB”, en Juristische Schulung, pp. 161-172.

Paulus, Rainer (1987): “Die 'falsche Aussage' als Zentralbegriff der $\$ \$ 153-163$ StGB”, en JusT et al. (edits.), Gedächtnisschrift für Günther Küchenhoff(Berlín, Duncker \& Humblot) pp. 435-456. 
Puppe, Ingeborg (2013): Comentario “267 StGB”, en Kindhäuser, Neumann y PaefFGEN (edits.), NomosKommentar, Strafgesetzbuch, tomo 3 (Baden-Baden, Nomos, cuarta edición).

Rodríguez, Luis y Ossandón, María Magdalena (2008): Delitos contra la función pública (Santiago, Editorial Jurídica, segunda edición).

Rojas, Luis Emilio (2012): "Historia dogmática de la falsedad documental", en Revista de Derecho de la Pontificia Universidad Católica de Valparaiso XXXIX, pp. 545-583.

SCHMidHÄUSER, Eberhard, (1961): "Aussagepflicht und Aussagedelikt”, en Rechts- und Staatswissenschaftliche Fakultät der Georg-August-Universität zu Göttingen (edits.), Göttinger Festschrift für das OLG Celle (Göttingen, Otto Schwarz \& Co.) pp. 207-237.

SCRUTON, Roger (1999): Filosofía moderna. Una introducción sinóptica (Santiago, Editorial Cuatro Vientos).

STEIn, Ulrich (2008): "Acerca del concepto de declaración falsa”, en Revista Electrónica de Ciencia Penal y Criminología 10-15, disponible en: < http://criminet.ugr.es/recpc/10/ recpc10-15.pdf> [última visita: 29/05/2013].

Vormbaum, Thomas (1987): Der strafrechtliche Schutz des Strafurteils (Berlín, Duncker Humblot).

Vormbaum, Thomas (2013): Comentario “Vor $\$ \$ 153$ ff." y “\$ 153 StGB”, en KindhäUSer, Neumann y Paeffgen (edits.), NomosKommentar, Strafgesetzbuch, tomo 2 (BadenBaden, Nomos, cuarta edición).

Wilenmann, Javier (2011): "La administración de justicia como un bien jurídico", en Revista de Derecho de la Pontifica Universidad Católica de Valparaíso 36, pp. 531-573.

Wilenmann, Javier (2013), "Injusto, tipo e imputación. La teoría de la antijuridicidad en la dogmática penal”, en MAÑALICH (edit.), La antijuridicidad en el derecho penal, cuatro estudios (a publicarse en Montevideo-Buenos Aires, B de F).

Wolf, Gerhard (1991): "Falsche Aussage, Eid und eidesgleiche Beteuerungen", en Juristische Schulung, pp. 177-184. 